\title{
ANGELA DE CAROLI
}

ANÁLISE DOS DADOS OBTIDOS COM O USO DO ESPECTROFOTÔMETRO DIGITAL INTRAORAL DE DUAS PORCELANAS DENTAIS APÓS DIFERENTES

TRATAMENTOS DE SUPERFÍCIE

São Paulo

2009 


\section{Angela De Caroli}

Análise dos dados obtidos com o uso do espectrofotômetro digital intraoral de duas porcelanas dentais após diferentes tratamentos de superfície

Tese apresentada à Faculdade de Odontologia da Universidade de São Paulo, para obter o título de Doutor, pelo Programa de Pós-Graduação em Odontologia.

Área de Concentração: Dentística

Orientador: Prof. Dr. Glauco Fioranelli Vieira

São Paulo 
Catalogação-na-Publicação

Serviço de Documentação Odontológica

Faculdade de Odontologia da Universidade de São Paulo

Caroli, Angela De

Análise dos dados obtidos com o uso do espectrofotômetro digital intraoral de duas porcelanas dentais após diferentes tratamentos de superfície / Angela De Caroli; orientador Glauco Fioranelli Vieira. -- São Paulo, 2009.

92p. : fig., tab., graf.; $30 \mathrm{~cm}$.

Tese (Doutorado - Programa de Pós-Graduação em Odontologia. Área de Concentração: Dentística) -- Faculdade de Odontologia da Universidade de São Paulo.

1. Porcelana dentária - Tratamento de superfície - Alterações de cor 2. Espectrofotômetro digital intraoral 3 . Dentística

CDD 617.675

BLACK D2

AUTORIZO A REPRODUÇÃO E DIVULGAÇÃO TOTAL OU PARCIAL DESTE TRABALHO, POR QUALQUER MEIO CONVENCIONAL OU ELETRÔNICO, PARA FINS DE ESTUDO E PESQUISA, DESDE QUE CITADA A FONTE E COMUNICADA AO AUTOR A REFERÊNCIA DA CITAÇÃO.

São Paulo,

Assinatura:

E-mail: angela@odontologia.net 


\section{FOLHA DE APROVAÇÃO}

Caroli A. Análise dos dados obtidos com o uso do espectrofotômetro digital intraoral de duas porcelanas dentais após diferentes tratamentos de superfície [Tese de Doutorado]. São Paulo: Faculdade de Odontologia da USP; 2009.

São Paulo, / /2009

\section{Banca Examinadora}

1) $\operatorname{Prof}(a) \cdot \operatorname{Dr}(a)$.

Titulação:

Julgamento:

Assinatura:

2) $\operatorname{Prof}(\mathrm{a}) \cdot \operatorname{Dr}(\mathrm{a})$.

Titulação:

Julgamento:

Assinatura:

3) $\operatorname{Prof}(a) \cdot \operatorname{Dr}(a)$

Titulação:

Julgamento:

Assinatura:

4) $\operatorname{Prof}(\mathrm{a}) . \operatorname{Dr}(\mathrm{a})$.

Titulação:

Julgamento:

Assinatura:

5) $\operatorname{Prof}(a) . \operatorname{Dr}(a)$.

Titulação:

Julgamento:

Assinatura: 


\title{
DEDICATÓRIA
}

\author{
À Ana Sofia e Wagner, \\ minha família, \\ por quem esperei \\ minha vida toda.
}

Ao muito querido mestre e amigo,

Prof. Glauco, por quem tenho profundo respeito e amizade. 


\section{AGRADECIMENTOS}

Ao querido Prof. Dr. Carlos Alberto Bragança Pereira e seus alunos Luciana Morita Ishihara e Tiago Mendonça pela ajuda na análise e interpretação estatística.

À Profa. Dra. Patrícia de Freitas pela disponibilização do espectrofotômetro digital.

Às Bibliotecárias Glauci Elaine Fidelis e Maria Cláudia Pestana pela normalização técnica da tese.

Ao CNPq. 
"Primeiro, tenha um ideal definido e viável - um objetivo, uma meta. Segundo, disponha dos meios necessários para atingir este ideal - sabedoria, dinheiro, materiais e métodos. Terceiro, adapte os meios ao ideal. As pessoas são caçadoras de ideais. A vida só tem sentido quando perseguimos um objetivo".

Aristóteles (384-322 A. C.) 
Caroli A. Análise dos dados obtidos com o uso do espectrofotômetro digital intraoral de duas porcelanas dentais após diferentes tratamentos de superfície [Tese de Doutorado]. São Paulo: Faculdade de Odontologia da USP; 2009.

\section{RESUMO}

Dentro do aspecto estético atual, a harmonia entre a cor do elemento dental e dos materiais restauradores é um dos quesitos mais relevantes e de maior dificuldade técnica. A utilização de aparelhos para a seleção de cor pelo método digital propõese a diminuir o aspecto subjetivo do processo de visão das cores, minimizando dessa forma possíveis falhas do processo. Este estudo simulou três situações clínicas em peças protéticas cerâmicas na forma de três tratamentos de superfície, um desgaste com ponta de carboneto de silício, um glazeamento a frio e um overglaze em forno para porcelana. Em seguida avaliou-se a interferência dos tratamentos na cor de duas marcas comerciais de porcelana, com e sem a presença de saliva, através do método objetivo de seleção de cor, com auxílio de um espectrofotômetro digital intraoral. Concluiu-se que não houve alteração de cor perceptível ao olho humano de nenhum material sob os tratamentos superficiais realizados, porém, entretanto nota-se uma mudança maior da cor para o tratamento overglaze em relação aos demais tratamentos; a diferença de cor causada pela presença de saliva na porcelana Noritake e os valores encontrados para a porcelana

Duceram foram valores perceptíveis ao olho humano treinado em seleção de cor; o tratamento overglaze na porcelana Duceram foi o que maior $\Delta \mathrm{E}$ promoveu, chegando próximo ao limite aceitável; na presença de saliva os valores de $\Delta \mathrm{E}$ todos aumentaram para a porcelana Noritake e diminuíram para a porcelana Duceram, 
indicando que as diferentes composições dos materiais alteram seu comportamento; a diferença entre as medidas com e sem saliva para a porcelana Noritake é mais evidente do que para Duceram; o aparelho é falho em algumas interpretações, mas é aceitável para o uso clínico de tomada de cor; o aparelho não é indicado para tomada de cor em estudos científicos; as análises dos dados $L^{*} a^{*} b^{*}$ não são condizentes com as leituras de cor pelas escalas Vita Classical e 3D Master.

Palavras-Chave: Porcelana; Cor; Espectrofotômetro 
Caroli A. Analysis of data from digital intraoral spectrophotometer of two dental porcelain after different surface treatments [Tese de Doutorado]. São Paulo: Faculdade de Odontologia da USP; 2009.

\section{ABSTRACT}

Considering the current aesthetic aspect, the harmony between the color of the tooth and dental restorative materials is one of the issues of greatest importance and technical difficulty. The use of apparatus for the selection of color by digital method proposes to reduce the subjective aspect of the vision of colors, thus minimizing possible failures of the process. This study simulated clinical situations in three prosthetic ceramic pieces in the form of three surface treatments, a scattering using silicon carbide bur, a cold glaze and an overglaze in ceramic oven. Then we evaluate the interference of the treatments on the color of the two porcelains, with and without the presence of saliva using the objective method of color matching, with the aid of a digital intraoral spectrophotometer. It was concluded that there was no change in color perceptible to the human eye of any material on the surface treatments carried out, however, there is a greater change in color for the treatment overglaze when compared to other treatments; the difference in color caused by the presence of saliva in the Noritake and the values found for all treatments in Duceram were visible to the human eye trained on color selection; the treatment overglaze on porcelain Duceram caused the highest $\Delta \mathrm{E}$, reaching the acceptable limit; in the presence of saliva values of $\Delta \mathrm{E}$ increased for Noritake and decreased for Duceram, indicating that the different compositions of materials can alter their behavior; the difference between measurements with and without saliva for Noritake porcelain is more evident 
than for Duceram; the device is deficient in some interpretations, but is acceptable for the clinical use of color matching; the equipment is not indicated for color matching in scientific studies; the analysis of the data $L^{*} b^{*}$ are not consistent with the readings of the color tabs Vita Classical and 3D Master.

Keywords: Porcelain; Color; Spectrophotometer 


\section{LISTA DE ILUSTRAÇÕES}

Figura 4.1 - Corpos de prova

Figura 4.2 - Material utilizado para o tratamento superficial T2 43

Figura 4.3 - Espectrofotômetro Easyshade 44

Figura 4.4 - Aparelho utilizado 44

Figura 4.5 - Posicionamento correto da sonda do espectrofotômetro. 45

Figura 4.6 - Orientações sobre o posicionamento da sonda do espectrofotômetro; a primeira posição é a correta, as demais são incorretas e levam a uma falha da leitura de cor da superfície. 45

Figura 4.7 - Escala Vita Classical. 46

Figura 4.8 - Escala Vita 3D Master 47

Figura 6.1 - Esquema de cor CIELab. 77

Figura 6.2 - Espaço de cor CIELab .77 
Gráfico 5.1 - Intervalos de confiança para L

Gráfico 5.2 - Comparação da luminosidade entre tratamentos, marcas e grupos sem e com saliva

Gráfico 5.3 - Comparação da luminosidade entre os grupos sem e com saliva. 65

Gráfico 5.4 - Intervalos de confiança para $\mathrm{a}^{*}$ 67

Gráfico 5.5 - Comparação da coordenada $a^{*}$ entre tratamentos, marcas e grupos sem e com saliva 68

Gráfico 5.6 - Comparação da coordenada a* entre os grupos sem e com saliva......69

Gráfico 5.7 - Intervalos de confiança para b* 71

Gráfico 5.8 - Comparação da coordenada b* entre tratamentos, marcas e grupos sem e com saliva 72

Gráfico 5.9 - Comparação da coordenada b* entre os grupos sem e com saliva......73

Gráfico 5.10 - Comparação dos valores de $\Delta \mathrm{E}$ para os diferentes tratamentos e materiais.

Gráfico 6.1 - Magnitudes comparadas de La*b* 81 


\section{LISTA DE TABELAS}

Tabela 4.1 - Temperatura e tempo de queima de cada camada de porcelana, recomendados pelos fabricantes

Tabela 4.2 - Resumo dos tratamentos de superfície realizados .44

Tabela 5.1 - Dados da leitura de cor pela escala Classical para a porcelana Noritake

Tabela 5.2 - Alterações da porcelana Noritake observadas na escala Classical com a presença de saliva em T0 (controle) 51

Tabela 5.3 - Alterações da porcelana Noritake observadas na escala Classical com a presença de saliva em T1 (Dura-Green) 51

Tabela 5.4 - Alterações da porcelana Noritake observadas na escala Classical com a presença de saliva em T2 (glazeamento a frio) 51

Tabela 5.5 - Alterações da porcelana Noritake observadas na escala Classical com a presença de saliva em T3 (overglaze) 51

Tabela 5.6 - Alterações da porcelana Noritake observadas na escala Classical sem saliva quanto aos tratamentos

Tabela 5.7 - Alterações da porcelana Noritake observadas na escala Classical com saliva quanto aos tratamentos

Tabela 5.8 - Dados da leitura de cor pela escala 3D Master para a porcelana Noritake. 
Tabela 5.9 - Alterações da porcelana Noritake observadas na escala 3D Master com a presença de saliva em T0 (controle)

Tabela 5.10 - Alterações da porcelana Noritake observadas na escala 3D Master com a presença de saliva em T1 (Dura-Green)

Tabela 5.11 - Alterações da porcelana Noritake observadas na escala 3D Master com a presença de saliva em T2 (glazeamento a frio).

Tabela 5.12 - Alterações da porcelana Noritake observadas na escala 3D Master com a presença de saliva em T3 (overglaze).

Tabela 5.13 - Alterações da porcelana Noritake observadas na escala 3D Master sem saliva quanto aos tratamentos.

Tabela 5.14 - Alterações da porcelana Noritake observadas na escala 3D Master com saliva quanto aos tratamentos

Tabela 5.15 - Dados da leitura de cor pela escala Classical para a porcelana Duceram 56

Tabela 5.16 - Alterações da porcelana Duceram observadas na escala Classical com a presença de saliva em T0 (controle)

Tabela 5.17 - Alterações da porcelana Duceram observadas na escala Classical com a presença de saliva em T1 (Dura-Green)

Tabela 5.18 - Alterações da porcelana Duceram observadas na escala Classical com a presença de saliva em T2 (glazeamento a frio)

Tabela 5.19 - Alterações da porcelana Duceram observadas na escala Classical com a presença de saliva em T3 (overglaze) 
Tabela 5.20 - Alterações da porcelana Duceram observadas na escala Classical sem saliva quanto aos tratamentos

Tabela 5.21 - Alterações da porcelana Duceram observadas na escala Classical com saliva quanto aos tratamentos

Tabela 5.22 - Dados da leitura de cor pela escala 3D Master para a porcelana Duceram

Tabela 5.23 - Alterações da porcelana Duceram observadas na escala 3D Master com a presença de saliva em T0 (controle)

Tabela 5.24 - Alterações da porcelana Duceram observadas na escala 3D Master com a presença de saliva em T1 (Dura-Green)

Tabela 5.25 - Alterações da porcelana Duceram observadas na escala 3D Master com a presença de saliva em T2 (glazeamento a frio).

Tabela 5.26 - Alterações da porcelana Duceram observadas na escala 3D Master com a presença de saliva em T3 (overglaze).

Tabela 5.27 - Alterações da porcelana Duceram observadas na escala 3D Master sem saliva quanto aos tratamentos

Tabela 5.28 - Alterações da porcelana Duceram observadas na escala 3D Master com saliva quanto aos tratamentos

Tabela 5.29 - Valores de $L$ apresentados pela porcelana Noritake 62

Tabela 5.30 - Valores de L apresentados pela porcelana Duceram. 62

Tabela 5.31 - Intervalos de confiança pra L 63

Tabela 5.32 - Interpretação da análise estatística dos valores de L para os diferentes tratamentos 
Tabela 5.33 - Interpretação da análise estatística dos valores de L para os diferentes materiais.

Tabela 5.34 - Valores de $\mathrm{a}^{*}$ apresentados pela porcelana Noritake. 66

Tabela 5.35 - Valores de $a^{*}$ apresentados pela porcelana Duceram 66

Tabela 5.36 - Intervalos de confiança para $\mathrm{a}^{*}$ 66

Tabela 5.37 - Interpretação da análise estatística dos valores de a* para os diferentes tratamentos.

Tabela 5.38 - Interpretação da análise estatística dos valores de a* para os diferentes materiais 68

Tabela 5.39 - Valores de b* apresentados pela porcelana Noritake. 70

Tabela 5.40 - Valores de $b^{*}$ apresentados pela porcelana Duceram 70

Tabela 5.41 - Intervalos de confiança para $b^{*}$ 70

Tabela 5.42 - Interpretação da análise estatística dos valores de b* para os diferentes tratamentos. 71

Tabela 5.43 - Interpretação da análise estatística dos valores de b* para os diferentes materiais 72

Tabela 5.44 - Diferença total de cor entre os valores iniciais e os diferentes tratamentos sem e com saliva para a porcelana Noritake. 74

Tabela 5.45 - Diferença total de cor entre os valores iniciais e os diferentes tratamentos sem e com saliva para a porcelana Duceram 74

Tabela 5.46 - Resumo dos resultados (valores médios de $L, a^{*}$ e b ${ }^{*}$ ) 76

Tabela 6.1 - Valores de variância entre $L, a^{*}$ e $b^{*}$ 81 


\section{LISTA DE ABREVIATURA E SIGLAS}

$\mathrm{mm}$

milímetro

CIE

Commission Internationale L'Eclairage (Comissão Internacional de lluminação) 


\section{LISTA DE SÍMBOLOS}

$\begin{array}{ll}{ }^{\circ} \mathrm{C} & \text { graus Celsius } \\ \mathrm{a}^{*} & \text { coordenada } \mathrm{a}^{*} \text { (sistema CIELab) } \\ \mathrm{b}^{*} & \text { coordenada } \mathrm{b}^{*} \text { (sistema CIELab) } \\ \mathrm{L} & \text { luminosidade (sistema CIELab) }\end{array}$

$\Delta \mathrm{E} \quad$ delta $\mathrm{E}$, diferença total de cor

$\Delta \mathrm{L} \quad$ delta $\mathrm{L}$

$\Delta \mathrm{a} \quad$ delta a

$\Delta b \quad$ delta $b$ 


\section{SUMÁRIO}

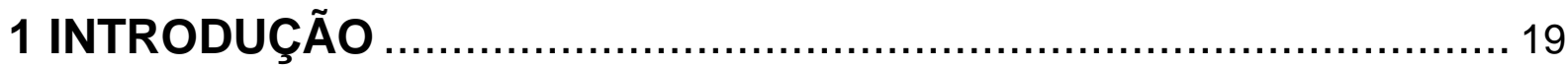

2 REVISÃO DA LITERATURA ................................................... 22

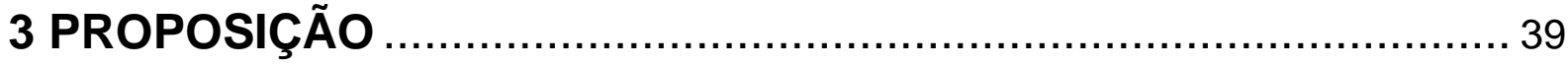

4 MATERIAL E MÉTODOS................................................... 40

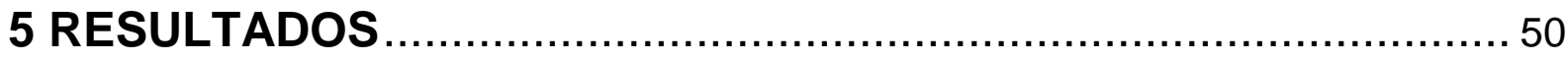

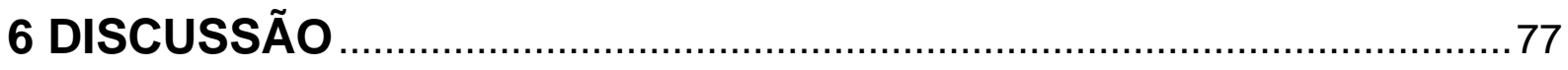

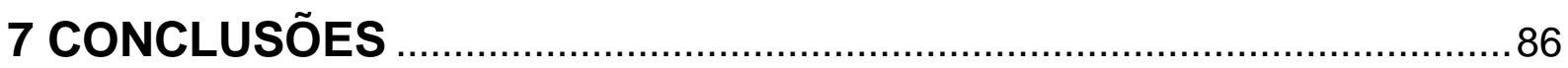

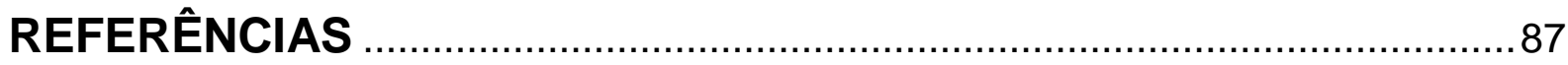




\section{INTRODUÇÃO}

A busca pela estética em Odontologia visa alcançar a expectativa do paciente e, ao mesmo tempo, superar as limitações das técnicas e tratamentos existentes. A correta escolha da cor de um elemento dental pelo profissional cirurgião-dentista durante um tratamento estético é um exemplo disto. O paciente espera que a substituição total ou parcial de seu dente seja perfeita. Já o profissional experiente reconhece, neste momento, a dificuldade de se fazer a correta tomada de cor do elemento, pois sabe que a cor, processo psicofísico de interpretação da luz que reflete sobre o objeto, quando se trata da estrutura dental, torna-se mais elaborada pela complexidade da interação entre esmalte dental, com sua textura e translucidez, e a dentina com suas diferentes propriedades (CARSTEN, 2003; FONDRIEST, 2003; SALESKI, 1972; VIEIRA et al., 2004). A cor é uma resposta psicológica a um fenômeno físico de transmissão ou reflexão da luz sobre um dado objeto. A complexidade da cor no caso de elementos dentais vem do fato de que parte da luz incidente em sua superfície é refletida pela superfície do esmalte e parte é transmitida através deste e refletida na superfície dentinária, no limite esmaltedentina. Ou seja, a cor do dente resulta da interação entre translucência e cor do esmalte por um lado, e opacidade e cor da dentina por outro (BALTZER; KAUFMANN-JINOIAN, 2005; TERRY, 2005a; VIEIRA et al., 2004). Uma peça cerâmica segue ao padrão do opaco cobrindo a cor de fundo, o metal sob a porcelana agindo como a camada de dentina, como uma barreira opaca, e a porcelana de corpo corresponde ao esmalte dental, quanto à translucência. 
Ainda podemos acrescentar a isso, a existência do metamerismo, um fenômeno óptico no qual dois objetos como dente e material restaurador, por exemplo, têm aparentemente a mesma cor sob determinada iluminação e alterandose as características do iluminante, as cores dos objetos tornam-se diferentes (VIEIRA et al., 2001).

Por fim, a dificuldade da correta escolha da cor dental aumenta devido ao fato do processo de visão da cor ser subjetivo, pois conta com a interpretação individual (ARMSTRONG, 1985; CULPEPER, 1970) e com o fato de que existe na população uma determinada porcentagem de indivíduos cor-deficientes (CAROLI; VIEIRA; PEREIRA, 2007).

$\mathrm{Na}$ tentativa de excluir o fator subjetivo durante a seleção de cor dental, existem no mercado odontológico alguns aparelhos como colorímetros e espectrofotômetros (BALTZER; KAUFMANN-JINOIAN, 2005). Os trabalhos mostram que estes aparelhos realizam a determinação da cor dental com maior reprodutibilidade e eliminam o caráter subjetivo do processo de visualização da cor. Com a constante inovação tecnológica, estes aparelhos estão sendo cada vez mais utilizados e prometem resultados seguros obtidos de maneira mais simples. Um modelo desses aparelhos é o espectrofotômetro digital fabricado pela Vita (Alemanha), denominado Vita Easyshade ${ }^{\circledR}$, o qual foi utilizado neste estudo.

Após a escolha da cor dental do paciente e confecção da peça protética, a mesma irá ser provada em boca e, depois de eventual ajuste oclusal, será cimentada. O desgaste que muitas vezes se faz necessário para ajustar a peça à oclusão do paciente ou para se realizar pequenas correções anatômicas do elemento protético, leva a perda do brilho e lisura da camada superficial da cerâmica conseguidos após o glaze durante o processo de confecção da peça. Esta alteração 
de superfície poderia levar a uma alteração da cor da peça. Em seguida, o profissional realiza um polimento da peça em boca na tentativa de polir novamente e conseguir o brilho superficial perdido após o ajuste, utilizando borrachas e pastas de polimento, processo também chamado de glazeamento a frio. Alguns profissionais preferem reenviar a peça ao laboratório com intuito de realizar uma nova aplicação de glaze. O técnico neste momento poderia aumentar o tempo ou a temperatura da peça no forno para obter maior brilho e lisura superficial desejados, processo este denominado overglaze. Entretanto, pode-se perguntar se estes processos poderiam acarretar uma alteração de cor da peça protética levando a um insucesso do trabalho.

Ainda pode-se perguntar se a presença ou não da saliva interferiria no processo de visualização da cor do material. Durante a prova de cor de uma peça protética, utiliza-se ou não a saliva do paciente para molhar a mesma, uma vez que ela estará cimentada na boca futuramente, assim, exposta à saliva. Estes são os questionamentos a que este trabalho se propõe tentar responder. 


\section{REVISÃO DA LITERATURA}

Para melhor entender o mecanismo de visualização das cores e correta comunicação sobre o assunto, faz-se necessário algum conhecimento sobre colorimetria, ciência de medição de cor que estabelece um método psicofísico internacional, onde se inclui um observador-padrão, um objeto observado e fontes de luz padronizadas. Este método tem suprido uma base operacional para todos os estudos sobre cor, permitindo medir-se o fenômeno subjetivo da percepção das cores (SPROULL, 1973).

É consenso entre os autores a definição de cor como uma resposta psicológica, portanto subjetiva, a um fenômeno físico, então pode ser considerada como um fenômeno psicofísico onde sempre temos a interpretação dos fatores físicos (o objeto, corantes, características de iluminação, etc.), sensoriais (detecção do estímulo pelo olho humano) e neurofisiológicos (interpretação cerebral do estímulo) (SHILLINGBURG, 1998; SPROULL; PRESTON, 2000; TOUATI, 2000).

Notamos que a visualização de cor é dependente de três fatores que devem sempre estar presentes e são avaliados por suas características. São eles:

$$
\begin{aligned}
& \checkmark \text { fonte iluminante } \\
& \checkmark \text { objeto observado } \\
& \checkmark \quad \text { olho do observador }
\end{aligned}
$$

Alterando-se qualquer um destes três fatores, a percepção "cor" também sofrerá alteração. Sendo assim, didaticamente, estudamos a parte física e a parte psicológica da cor. A parte física pode ser medida, reproduzida e modificada sob três propriedades: matiz (o nome da cor propriamente dita, que as separam em 
diferentes famílias, como vermelho, azul, verde ou amarelo); saturação (o quão vermelha, ou azul, ou amarela dentro de cada família é a cor, ou seja, a quantidade de matiz em cada cor) e luminosidade (quantidade de cinza presente na cor ou intensidade da cor). Esse conceito já foi definido há muitas décadas, foi ordenado por Munsell (1961), e perdura até os dias de hoje.

Já a parte psicológica da cor é a interpretação feita por um indivíduo e, portanto, é subjetiva. A percepção das cores varia entre indivíduos, pois sofre a influência de inúmeras variáveis físicas e, principalmente, psicológicas (VIEIRA, 1996; VIEIRA et al., 2001). De longe, a parte mais complexa e não compreendida sobre a sensação de cor é a detecção da energia radiante pelos receptores nos olhos humanos e a interpretação deste estímulo visual pelo cérebro (SALESKI, 1972). Comprovando esta dificuldade, Armstrong (1985) relatou em seu trabalho que um mesmo dentista pode escolher uma determinada cor em uma primeira tomada de cor e, numa segunda vez, sob condições similares, escolher uma cor diferente da escolha feita anteriormente.

A determinação da cor em seu aspecto físico é chamada de reflectância espectrofotométrica (medição através de aparelhos da luz refletida por um objeto), e em seu aspecto psicológico é traduzida em parâmetros de triestímulos dos cones (células fotorreceptoras) presentes na retina humana.

Numerosos autores, desde muito, sugerem em suas pesquisas que 0 processo de escolha de cor seja treinado desde o ambiente acadêmico e que as informações necessárias para sua compreensão possam ser ensinadas como acima descritas (BARNNA et al., 1981; CONCEIÇÃO, 2000; SPROULL, 1974). 


\subsection{Método Visual ou Subjetivo}

Podemos descrever as variáveis que participam e influenciam no processo de seleção de cor dental pelo método visual, como sendo:
$\checkmark$ Físicas
$\checkmark$ Fisiológicas
$\checkmark$ Psicológicas
$\checkmark$ Dentais
$\checkmark$ Outras

As variáveis físicas são facilmente entendidas como anteriormente descritas, matiz, saturação e luminosidade (SORENSEN; TORRES, 1987; SPROULL, 1973).

As variáveis fisiológicas como a idade do observador, sexo presença de discromatopsias ou doenças oculares, são variáveis importantes neste processo. Indivíduos com idade mais avançada já apresentam um desgaste do cristalino ocular e outras degenerações do órgão que interferem na visão das cores. Também existem trabalhos que identificaram as diferenças de seleção de cor entre homens e mulheres, quer pelo aspecto psicológico, quer pelo aspecto da incidência de defeitos de visão colorida que têm etiogenia genética como é o caso da discromatopsia vermelho-verde, mais conhecida como daltonismo e outras menos conhecidas (CAROLI; VIEIRA; PEREIRA, 2007).

As variáveis psicológicas foram estudadas por Carsten (2003), que relatou em seu estudo que o estado de ânimo do observador altera a seleção de cor, o 
mesmo valendo para fatores como fadiga e alterações de humor; e ainda que as experiências vividas pelo observador também influenciam no processo.

Já as variáveis dentais são numerosas e claramente compreendidas no processo de visualização da cor dental. Qualquer alteração ou característica marcante no esmalte ou na dentina influenciam a cor dental, características como a espessura e translucidez do esmalte, presença de outros efeitos de esmalte como hipoplasias e manchas intrínsecas, defeitos horizontais e verticais do esmalte, efeitos ópticos e de forma, amarelamento hereditário da cor e opacidade da dentina, espessura dentinária (BALTZER; KAUFMANN-JINOIAN, 2005; FONDRIEST, 2003).

Podemos ainda mencionar outras variáveis como o metamerismo (situação na qual dois objetos têm condicionalmente a mesma cor sob determinado iluminante), a influência do ambiente no processo de visão das cores, como por exemplo, a influência das cores das paredes ou dos tecidos ao redor do objeto que refletem cor no momento da seleção da cor ou ainda a própria dificuldade da comunicação de cor entre dois ou mais indivíduos, como ocorre na comunicação entre paciente-dentista ou dentista-técnico de prótese (FONDRIEST, 2003).

O método visual de seleção de cor dental consiste na comparação entre a estrutura dental cuja cor está sendo escolhida e um dos "dentes" ou "tabs" da escala de cor que está sendo usada. A cor da escala que mais se aproximar será escolhida como a cor dental. Sendo assim, encontramos trabalhos que avaliaram as escalas desde meados do século passado e relataram algumas limitações das escalas convencionais conhecidas, como o fato de que elas não cobriam todo o espectro de cor dos dentes naturais, não havia um arranjo lógico da distribuição das cores e apresentavam diferentes propriedades ópticas dos materiais em relação ao dente (HASEGAWA; IKEDA; KAWAGUCHI, 2000; PRESTON, 1985; SCHWABACHER; 
GOODKIND, 1990; SORENSEN; TORRES, 1987; SPROULL, 1973;). Com a mais nova escala utilizada atualmente, 3D Master (Vita, Alemanha) os estudos mostram que a habilidade desta em selecionar a cor dental é mais confiável e que a distribuição de cor da escala é mais ordenada quando comparada à distribuição das escalas anteriores (AHN; LEE, 2008; CORCIOLANI et al., 2009), porém há relatos de que as escalas existentes ainda continuam apresentando tais limitações além de não serem específicas para uma dada população, não atendendo totalmente ao seu propósito (ANALOUI et al., 2004; WEE et al., 2005).

O resultado clínico de diferentes sistemas de escalas de cor na seleção dental mostrou que profissionais com menor experiência clínica necessitam de um sistema que os guiem durante o processo visual de maneira sistemática para terem mais sucesso em sua tarefa (HAMMAD, 2003; HASSEL et al., 2005; WEE et al., 2005). Esta é a uma das razões pelas quais alguns autores descrevem o aprendizado do assunto cor também como facilitação do processo visual (CAROLI; VIEIRA; PEREIRA, 2007; CONCEIÇÃO, 2000; SPROULL, 1974).

O resultado final da seleção de cor pelo método visual leva a insucessos como podemos ver em estudos que encontraram escolhas diferentes em momentos diferentes, para um mesmo objeto e mesmo observador (ARMSTRONG, 1985). A concordância inter-observadores pelo método visual foi descrita como de $26,6 \%$ (3 observadores) a 46,6\% (2 observadores) segundo os achados de Paul et al. (2002). Klemeti et al. (2006) também afirmaram que a variação na seleção de cor interobservadores é moderada a alta e que o uso de um colorímetro pode ser útil como ferramenta educacional. Ao avaliar a cor de coroas cerâmicas, estudos mostraram que aproximadamente $60 \%$ delas têm pequenos desvios na coloração e $45 \%$ apresentaram diferenças de cor em relação à estrutura dental adjacente (ROSA; 
BONA, 2007). Kawaragi et al. (1990) quantificaram o índice de sucesso quanto ao acerto de cor de substituições dentais pelo método visual e encontraram $80 \%$ de pacientes insatisfeitos quanto à cor de dentes substituídos.

Wee et al. (2005) relataram que a cor final deve ainda ser escolhida através de um consenso entre profissional e paciente e que o método digital deveria ser conjuntamente usado como rotina na escolha da cor dental durante o processo de confecção das coroas cerâmicas.

\subsection{Método digital ou objetivo}

O método digital oferece avaliações objetivas da leitura de cor e diz fornecer resultados precisos, quantificáveis e repetíveis, que aumentam o índice de sucesso na seleção e comunicação da cor e facilita o adequado registro dos parâmetros relacionados às cores em pesquisa científica (CHU; TARNOW, 2001; ISHIKAWA-NAGAI et al., 2005; ROSA; BONA, 2007; TERRY, 2005b). Utiliza aparelhos como as câmeras digitais, softwares de imagem, os colorímetros ou os espectrofotômetros, todos consistindo de um detector, um condicionador de sinal e um software que processa o sinal (BREWER; WEE; SEGHI, 2004).

Kim-Pusateri et al. (2009) testaram a confiabilidade (capacidade de reprodução dos mesmos resultados) e a precisão de quatro aparelhos para seleção de cor, todos espectrofotômetros. Seus resultados mostraram que eles têm alta confiabilidade, acima de $96 \%$ indicando valores de cor previsíveis; e acuidade de 67 
a 93\% sendo que encontraram diferenças significantes entre as comparações feitas entre os aparelhos.

Os colorímetros analisam os valores para o vermelho, verde e azul, refletidos através de filtros que simulam os receptores do olho humano. Os triestímulos $X, Y, Z$ são convertidos em coordenadas $L$, $a^{*}$ e b* do sistema CIELab. O uso dos sistemas de coordenadas possibilita interpretar e definir objetivamente os fenômenos físicos na percepção instrumental da cor. Já os espectrofotômetros medem e registram a quantidade de luz radiante refletida ou transmitida de um objeto através de seu comprimento de onda. Este registro é obtido nas coordenadas $\mathrm{La}^{*} \mathrm{~b}^{*}$.

Segundo Macedo (1976), espectrofotômetros são aparelhos compostos por uma fonte luminosa estável, um dispositivo de radiação monocromática, amplo padrão de comparação e dispositivo de detecção de radiação (são colorímetros em que se dispõe de uma grande faixa contínua de comprimentos de onda e de dispositivos de seleção, comparação e medida que tornam muito mais acuradas as suas determinações.

Os espectrofotômetros mais precisos são aqueles de esfera de integração, chamados ópticos esféricos, nos quais o objeto é exposto à luz em diferentes ângulos e direções durante a sua análise. Na boca, como a janela de leitura é muito pequena, a luz é difusa e dirigida para a superfície do dente em apenas um sentido (VOLPATO; BARATIERI; MONTEIRO JR., 2005). As medições de cor espectrofotométricas são capazes de quantificar de forma confiável a cor tanto de dentes como de porcelana dental. O desempenho da seleção de cor foi significantemente maior pelo método computadorizado nos achados de Jarad, Russell e Moss (2005) quando comparados ao método convencional. 
Tung et al. (2002) avaliaram a capacidade de repetição da leitura de cor de um colorímetro intraoral e compararam a leitura de cor com o método visual através da observação por dois profissionais experientes e constataram que o aparelho concordou com suas próprias leituras em $82 \%$ das vezes e os profissionais concordaram consigo mesmos em $73 \%$ das vezes. Entre si, os dois métodos concordaram em $55 \%$ das vezes. Os autores concluíram que o método objetivo é superior ao método visual.

Nos estudos de Horn, Bulan-Brady e Hicks (1998), vinte dentes extraídos foram avaliados por cinco indivíduos e por um espectrofotômetro em dois momentos diferentes. Os autores relataram que a avaliação instrumental teve concordância de $80 \%$ enquanto que a avaliação humana teve concordância de 20 a $60 \%$ variando o examinador. Assim, os autores concluem que a avaliação instrumental foi mais confiável e que pode oferecer um método mais previsível e acurado para avaliação de cor in vitro.

Outra vantagem da leitura digital seria a diminuição significativa no tempo necessário para se determinar a cor medida (RAIGRODSKI et al., 2006).

Já segundo Paul et al. (2004) em um estudo in vivo comparativo entre os métodos visual e instrumental de avaliação de cor em 10 indivíduos e 3 examinadores, a análise de cor com o espectrofotômetro foi achada superior. Nove entre dez coroas realizadas com a seleção objetiva foram preferidas às convencionais quando avaliadas visualmente pós-cimentação e também nove entre dez coroas tiveram a menor diferença de cor medida $(\Delta \mathrm{E})$ pelo espectrofotômetro quando a cor havia sido escolhida pelo método objetivo.

Em outro estudo, Paul et al. (2002) observaram a cor do incisivo central de 30 pacientes pelo método objetivo e visual (3 examinadores) em 3 tomadas de cor e 
obtiveram $26,6 \%$ de concordância entre os observadores humanos e $83,3 \%$ de concordância entre as tomadas digitais. Além disso, em $93,3 \%$ dos caos o $\Delta \mathrm{E}$ da tomada visual é maior que da tomada digital, concluindo assim que a análise digital é mais acurada e mais reprodutível quando comparada com a avaliação humana de cor.

Mais recentemente, outro trabalho comparou a eficiência do método digital sobre o convencional; os autores confeccionaram 72 coroas para 36 pacientes, uma pelo método convencional de tomada de cor e outra com auxílio do espectrofotômetro e mediram $\circ \Delta \mathrm{E}$ de ambas. Três examinadores calibrados escolhiam as melhores coroas. Os resultados mostraram que a média de $\Delta \mathrm{E}$ foi significantemente menor paras as coroas construídas pelo método digital e estas tiveram menor taxa de rejeição (SILVA et al., 2008).

Em contrapartida, os autores descrevem o custo elevado doa aparelhos como sua principal desvantagem e também o tamanho de alguns equipamentos como outra característica negativa (ROSA; BONA, 2007).

Chu (2003) em seu capítulo Color, descreve os sistemas de seleção de cor baseados em tecnologia como possuidores de vantagens distintas sobre o método convencional, a captura da imagem toma pouco tempo e não causa maior desidratação do dente, além de que a cor da restauração protética pode ser verificada antes da colocação intraoral. Entretanto, a desvantagem predominante atualmente é o custo dos aparelhos e também os gastos com pesquisa e desenvolvimento dos sistemas. A interpretação dos relatórios ainda é subjetiva, ou seja, necessitam da habilidade e conhecimento do técnico que fabrica a peça. Se a determinação da cor pode ser dividida em quatro subitens críticos - análise, comunicação, interpretação e fabricação - os sistemas baseados em tecnologia 
dominam os temas análise e comunicação muito bem. Interpretação e fabricação da peça protética ainda são subjetivas.

Além disso, estes aparelhos não são totalmente à prova de falhas, os dados obtidos podem sofrer alterações devido à dispersão da luz nas superfícies curvas dos dentes e à menor precisão das leituras realizadas em corpos translúcidos, comparadas às realizadas em corpos opacos (ROSA; BONA, 2007).

Existem poucos trabalhos que avaliam o uso do método digital como menos eficiente quando comparado ao método convencional. Klemetti et al. (2006) compararam a tomada de cor feita por dentistas pouco experientes e um colorímetro e constataram que a repetibilidade humana havia sido de 33 a $43 \%$ e a concordância do aparelho também havia sido baixa, 8 a 34\%. Em sua conclusão os autores sugerem que o uso do aparelho no ensino e padronização do processo de seleção de cor pode ser uma eficiente ferramenta.

Em outro trabalho mais amplo, os autores observaram a cor de 342 dentes in vivo e compararam o método convencional com o digital através de 3 aparelhos. Segundo os autores, as deficiências dos instrumentos assim como da detecção visual ficaram evidentes no estudo, pois a concordância do método visual (a mesma leitura para todos os examinadores) ficou em $36,7 \%$ e para o digital ficou em $9,9 \%$ na média para os três aparelhos. O melhor nível de acerto da cor foi realizado pelos examinadores humanos $(52,9 \%)$ comparada aos aparelhos (31,3\% em média). (HUGO; WITZEL; KLAIBER, 2005)

Okubo et al. (1998) testaram a reprodutibilidade de um colorímetro e compararam-na com o método visual. Os resultados mostraram que o colorímetro repetiu $100 \%$ suas leituras enquanto o método visual apresentou falha de repetibilidade. Quanto ao acerto das leituras (31 observadores e uma amostra in 
vitro) ambos os métodos não mostraram diferenças estatisticamente significante (50\% para o digital e $48 \%$ para o visual).

Wee et al. (2000) testaram a seleção de cor com um colorímetro, a escala 3D Master e a escala Vita Lumin Vaccum. A porcentagem de cores selecionadas aceitáveis clinicamente foi de $46,67 \%$ para a escala Vita Lumin Vaccum, $40 \%$ para o colorímetro e 56,67\% para a 3D Master mostrando nenhuma diferença significante entre os grupos. Os dois últimos sistemas, considerados novos à época, não produziram um sistema de seleção de cor melhor que o convencional.

Em 2002, Wee, Monaghan e Johnston testaram a seleção de discos de porcelana in vitro através do método visual utilizando as escalas 3D Master e Vita Lumin e do método digital através do colorímetro Shofu Shade Eye e concluíram que, independente do método utilizado para a seleção de cor, uma restauração de cor apropriada não pode ser garantida.

Dancy et al. (2003) realizaram um estudo onde quarenta pacientes foram avaliados, vinte pelo método visual convencional quanto à seleção de cor e vinte por análise fotocolorimétrica; quarenta coroas cerâmicas foram construídas utilizando-se os dois sistemas aleatoriamente. No momento da cimentação, as coroas tiveram sua cor medida por um espectrofotômetro e a diferença de cor foi calculada pelo aparelho. Os resultados mostraram que a média de $\Delta \mathrm{E}$ pela avaliação visual foi de 10,49 enquanto no grupo digital foi de 8,99 . Os dados não mostraram diferenças estatisticamente significantes entre os métodos. Assim os autores afirmaram que o uso de técnicas fotocolorimétricas pode servir como uma alternativa confiável ao método visual de seleção de cor e que este seria um método útil para clínicos que têm dificuldade no processo. 


\subsection{Cerâmicas odontológicas}

As cerâmicas podem ser definidas como materiais compostos por uma combinação de elementos metálicos ( $\mathrm{Al}, \mathrm{Ca}, \mathrm{Li}, \mathrm{Mg}, \mathrm{K}, \mathrm{Na}, \mathrm{Zr}$, Ti) e não metálicos $(\mathrm{O}, \mathrm{Si}, \mathrm{B}, \mathrm{F})$. Quando comparadas aos outros materiais usados nas técnicas indiretas apresentam vantagens que explicam sua crescente popularidade. A capacidade de reproduzir os complexos fenômenos ópticos observados na estrutura dental. É considerada excelente quando comparadas a outros materiais estéticos. Outra vantagem é ser considerado o material mais biocompatível para se realizar restaurações dentárias. Esta característica esta intimamente ligada à capacidade de manter a cor e a textura por períodos prolongados de tempo, apresentando alta estabilidade química e alta resistência a abrasão. Entretanto, algumas características indesejáveis impedem o uso irrestrito das cerâmicas odontológicas, como por exemplo, a sua baixa tenacidade à fratura e ao seu alto potencial de desgastar o esmalte do dente antagonista, principalmente quando sua superfície se encontra rugosa ou quando o paciente apresenta hábitos parafuncionais, como o bruxismo.

As porcelanas feldspáticas são um dos tipos de cerâmicas, obtidas a partir de caulim (argila), quartzo e feldspato, sendo este último o seu principal constituinte (ao redor de 60\%). Elas se caracterizam por apresentar uma matriz vítrea (amorfa), cujos constituintes são $\mathrm{SiO} 2$ (60\%), Al2O3, Na2O e K2O. Grande parte das porcelanas apresenta partículas cristalinas dispersas nesta matriz, como por exemplo, a leucita (K2O.Al2O3.4SiO2), a alumina ou a fluorapatita. Entretanto, algumas delas podem não apresentar a fase cristalina. A leucita á a principal fase 
cristalina utilizada nesses materiais e seu conteúdo, em volume, pode variar de 5 a $30 \%$. As partículas de leucita têm formato equiaxial ou dendrítico e podem estar homogeneamente dispersas na matriz vítrea, ou formando aglomerados.

A maior parte das porcelanas é produzida a partir do feldspato. Esse mineral é extraído da natureza e passa por um processo de purificação para remoção de contaminantes como o ferro, que causam escurecimento do produto final. $O$ feldspato purificado é então misturado a quartzo e fundentes e aquecido a altas temperaturas $\left(1300^{\circ} \mathrm{C}\right)$. Nessas temperaturas, o feldspato sofre uma fusão incongruente, ou seja, se decompõem em uma fase vítrea com cristais de leucita dispersos em seu interior. O controle da quantidade de leucita pode ser feito pelo fabricante por meio de tratamentos térmicos, e também se adicionando leucita sintética. Após o aquecimento a altas temperaturas, o material é resfriado bruscamente, provocando fratura da massa e gerando o que se chama de frita. Essa frita passa então por uma série de moinhos de bolas de zircônia para controlar a distribuição de partículas de pó final. Os fabricantes acrescentam nesta fase os pigmentos (óxidos metálicos) que dão à porcelana a cor e fluorescência semelhantes a do dente natural. O produto final é um pó muito fino que é fornecido em potes juntamente com um líquido para modelar.

Os óxidos para pigmentação são adicionados à porcelana dental no intuito de obter as diversas tonalidades para a simulação dos dentes naturais. Estes pigmentos corantes são produzidos pela fusão conjunta de óxidos metálicos, partículas pequenas de vidro e feldspato. Após isto, eles são moídos para obtenção de pós, que são misturados com a porcelana em pó não pigmentada e aquecidos de modo a se conseguir o matiz e a tonalidade desejados (CRAIG; POWERS, 2004; PHILLIPS, 1993). 
São exemplos desses pigmentos:

óxido de titânio: matizes amarelo-marrons

óxido de manganês: matiz púrpura

óxido de ferro ou níquel: matiz marrom

óxido de cobalto: matiz azul

óxidos de cobre ou cromo: matiz verde

óxido de lantanídeo: fluorescência

óxidos de titânio, zircônio, estanho: opacificadores

Como vantagens das porcelanas pode-se mencionar sua excelente propriedade óptica (capacidade de mimetizar o dente humano), sua biocompatibilidade, estabilidade de cor e textura superficial, e alta resistência à abrasão. Suas desvantagens são sua baixa tenacidade à fratura e provocar grande desgaste dental antagonista (PHILLIPS, 1993).

Existe uma grande literatura sobre este tema, pois é um material desde muito estudado e testado em Odontologia. Porém, nem tanta pesquisa foi realizada no que se refere a mudanças de cor relacionadas com alterações de características superficiais. Sarac et al. (2006) mostraram os efeitos dos diferentes sistemas de polimento de porcelana feldspática sobre sua cor e textura de superfície. Os autores testaram quatro diferentes técnicas de polimento de porcelana em noventa espécimes e mediram a cor dos mesmos utilizando um colorímetro de acordo com o sistema CIELab além de calcularem o $\Delta \mathrm{E}$ entre o grupo controle apenas com glaze e os grupos experimentais. Também mediram a rugosidade superficial Ra de cada técnica. Os autores constataram que todas as técnicas de polimento afetaram significativamente a cor da cerâmica feldspática. $\mathrm{O}$ valor de $\Delta \mathrm{E}$ variou de 1,03 a 3,36, valores considerados dentro do nível aceitável clinicamente. 
Quando uma peça em porcelana é provada, ou após ter sido desgastada para ajuste em boca, sua cor é diferente da cor após o glazeamento. Isto pode estar relacionado com a falta de avaliação do aspecto superficial. A cor é uma característica do objeto. A energia luminosa, entretanto, tem seu valor qualitativo e quantitativo em relação à reflexão e/ou transmissão diretamente associada com o aspecto de superfície (BILMEYER; SALTZMAN, 1981). Este fenômeno é raramente considerado, apesar de que mesmos objetos com diferentes superfícies possam apresentar cores diferentes. Ainda sabemos que alguns autores relataram a importância do fenômeno conhecido como metamerismo onde dois objetos diferentes podem ter cores ora semelhantes, ora diferentes, dependendo do iluminante em questão (KIM et al., 2007; LEE, 2007). Entretanto, Ferreira (2001) mostrou que esta interferência do iluminante não é tão significativa na cor final entre dois objetos como descreve a literatura. Al-Wahadni (2006) observou que diferenças significantes na lisura superficial ocorreram dentre as técnicas de polimento testadas. O autor relata que independente da marca ou do pré-tratamento, toda cerâmica ajustada deveria ser novamente glazeada ou sujeita à sequência de polimento seguida do estágio final de polimento com pasta diamantada (glazeamento a frio).

A palavra inglesa glaze significa dar brilho ou lustro a uma superfície. Quando a porcelana atinge sua temperatura final de queima, ela apresenta uma superfície regular e mantendo-se esta temperatura por alguns segundos ela torna-se mais brilhante e mais translúcida. Esta etapa é conhecida como alto biscuit ou glaze natural da porcelana, sendo este o ponto em que a porcelana atinge melhor lisura. Além do brilho, o glaze fecha as fendas que porventura existam na superfície, o que dificulta o acúmulo de placa bacteriana (AGRA, 2005). 
A cor e brilho superficiais obtidos inicialmente pelo glaze de uma peça cerâmica podem ser conseguidos durante o processo de prova da peça protética molhando-se a superfície da mesma com a saliva do paciente. Entretanto, a lisura superficial e rugosidade só poderão ser restabelecidas com novo glaze em forno realizado em laboratório. Assim, alguns autores têm se preocupado em avaliar a cor final da peça após queimas repetidas em forno durante o processo de fabricação da peça. Uludag et al. (2007) em um estudo in vitro concluíram que o número de queimas da cerâmica provoca mudanças perceptíveis nos parâmetros de La*b*.

Ozturk et al. (2008) confeccionaram trinta corpos de prova de duas marcas comerciais de cerâmica com três diferentes espessuras e testaram a cor sob diferentes números de queimas da cerâmica, 3, 5, 7 e 9. Os autores afirmaram que todos os parâmetros de La*b* foram afetados pelas marcas de cerâmicas com composições diferentes, pela espessura do material e pelo número de queima.

Souza et al. (2009) em um trabalho semelhante afirmaram que os corpos de prova se tornaram mais escuros, mais amarelos e mais vermelhos com o aumento do número de queimas.

Contrariamente, Celik et al. (2008) afirmaram que queimas repetidas produziram aumento da luminosidade e diminuição do valor de $\mathrm{a}^{*}$, tornando os corpos de prova menos vermelhos; e aumentando o valor de $b^{*}$ tornando-os mais amarelos em apenas um dos matizes testados, o que nos leva a crer que tais alterações não podem se generalizadas mas sim determinadas pela composição das diferentes marcas comerciais e matizes. Os autores também relataram que tais alterações eram clinicamente aceitáveis.

Ainda testando corpos de prova em cerâmica, Dozic et al. (2003) estudaram a influência da espessura das camadas de porcelana na cor da restauração final e 
concluíram que pequenas mudanças na espessura da mesma e a cor das camadas de opaco e translúcido podem influenciar a cor final de espécimes feitos de camadas de porcelana. Quanto maior a camada de opaco, maiores os valores de $a^{*}$ e $b^{*}$ em todas as cores e em $L$ dependendo do tom utilizado. 


\section{PROPOSIÇÃO}

O objetivo deste estudo foi analisar os dados de cor obtidos pelo aparelho Vita Easyshade e avaliar a influência de diferentes texturas superficiais de cerâmica, com ou sem a camada de saliva, sobre a cor final do material. 


\section{MATERIAL E MÉTODOS}

Duas marcas comerciais de porcelana feldspática foram usadas: DUCERAM KISS (Degudent-Dentsply, Alemanha), lote ํㅜ 50336 e SUPER PORCELAIN EX-3 (Noritake, Japão), lotes no009494 e 001036. A cor escolhida foi dentina- A3. Optouse pela não utilização de fundo opaco para que os espécimes não sofressem interferência de variações da espessura do mesmo que pudessem alterar sua cor final, como sugerido por Dozic et al. (2003). Trinta corpos de prova foram confeccionados por apenas um operador com intuito de obter-se maior padronização. A mistura pó e líquido foi feita sobre uma placa de vidro utilizando-se uma espátula para cimento №24. Então, utilizando-se um molde plástico cilíndrico, cada corpo de prova foi confeccionado com aproximadamente 2,00 $\mathrm{mm}$ de espessura X 1,20 mm de diâmetro. Cinco corpos de prova por vez foram colocados sobre uma lâmina de lã de vidro e levados ao forno de porcelana para que não houvesse desigualdade na qualidade da cocção existente quando um volume grande de cerâmica é queimado de uma só vez. Para a confecção dos corpos de prova foi utilizado um forno odontológico Phoenix Quick Cool (Ceramco-Dentsply, Estados Unidos) calibrado conforme orientação do fabricante. A temperatura e tempo de queima de cada fase foram determinados segundo as recomendações de cada fabricante, conforme a tabela 4.1. 


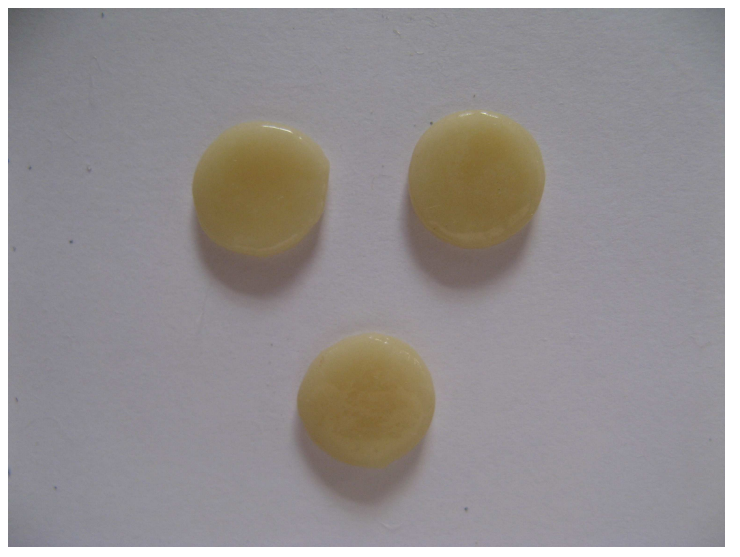

Figura 4.1 - Corpos de prova

Foi realizada a queima da primeira camada de porcelana. Em seguida, uma nova camada de porcelana foi aplicada ao corpo de prova para regularizar possíveis imperfeições superficiais e the proporcionar a correta espessura. Realizou-se então, a queima da segunda camada. Se necessário, algum ajuste de espessura ou imperfeições foi agora retirado com uma broca diamantada 4138 (KG Sorensen, Brasil) em alta rotação e sob refrigeração; os corpos de prova voltaram ao forno para a queima final do glaze natural. A qualidade final do glaze foi aferida visualmente e a presença de bolhas ou irregularidades acentuadas resultou no descarte do espécime e confecção de novos corpos de prova (Figura 4.1).

Após a queima da camada de glaze, todos os corpos de prova encontravamse no instante considerado T0 e a medida de cor de cada um deles foi realizada neste momento utilizando-se 0 espectrofotômetro digital Easyshade (Vita, Alemanha) de duas formas, sem saliva artificial (Grupo A) e com saliva artificial (Grupo B).

O aparelho Easyshade consiste em um pequeno espectrofotômetro conectado a uma base por um cabo de fibra óptica. A ponta do espectrofotômetro que entra em contato com o objeto a ser avaliado tem $5 \mathrm{~mm}$ de diâmetro e possui 20 fibras ópticas, 13 responsáveis pela iluminação, quatro pela espectrofotometria e 
três detectores de angulação e movimento. A luz refletida pelo objeto é absorvida pelas fibras responsáveis pela espectrofotometria e os estímulos luminosos são conduzidos por um cabo até a base que os interpreta. Os resultados são fornecidos de acordo com as escalas Vitapan Classical e Vitapan 3D Master, além dos valores CIELab.

$\mathrm{Na}$ sequência, cinco corpos de prova receberam um tratamento superficial promovendo-se um desgaste com uma pedra abrasiva impregnada com óxido de alumínio Dura-Green formato 31-PC2 (Shofu, USA) utilizada em baixa rotação sem refrigeração, simulando-se um ajuste oclusal. Após este tratamento denominado T1, este grupo teve sua cor tomada pelo mesmo espectrofotômetro anteriormente utilizado, Easyshade, sem e com saliva (Grupos A e B).

No grupo chamado T2, cinco corpos de prova receberam o mesmo desgaste promovido em T1 e depois receberam um tratamento superficial considerado um glaze a frio: um polimento com roda de silicone impregnada com carbureto de silício de granulação média EVE Keramik R22NK (EVE, Alemanha), uma ponta de silicone para polimento de cerâmica (Renfort, Alemanha) e o disco de feltro (Renfort, Alemanha) montado em mandril para peça reta impregnado com pasta contendo partículas finas de diamante - Crystar Past (Kota Ind. e Com. Ltda., Brasil). Ao término, os cinco corpos de prova tiveram sua cor tomada como da maneira anterior, sem e com saliva (grupos A e B). Os polidores foram empregados de acordo com as instruções do fabricante, evitando uma compressão excessiva sobre os corpos de prova e realizando-se pequenos movimentos circulares. O tempo médio de aplicação de 60 segundos foi o suficiente para que se verificasse o efeito de cada um dos polidores sobre a superfície (Figura 4.2). 
Por fim, cinco corpos de prova voltaram ao forno e sofreram uma nova queima considerada um overglaze com valores conforme descritos na tabela 4.1. Este tratamento foi chamado T3 e simulou o que eventualmente pode ocorrer no processo de construção de uma peça cerâmica. Embora não seja o desejado, durante a confecção da peça protética, muitas vezes se faz necessária uma nova queima da mesma, ou ainda, uma queima por tempo e temperatura excessivos pode ocorrer acidentalmente. A cor dos corpos de prova foi tomada também como anteriormente descrito, grupos A e B.

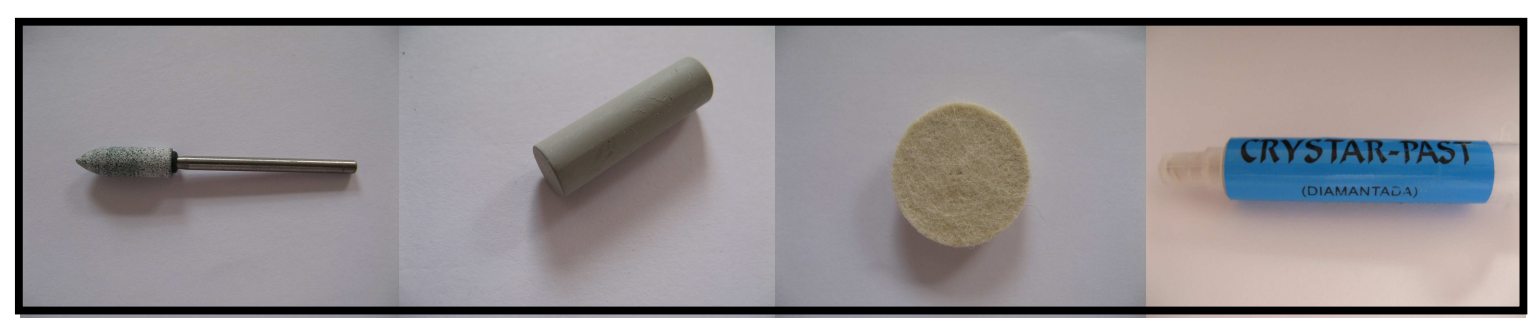

Figura 4.2 - Material utilizado para os tratamentos superficiais T1 e T2

Tabela 4.1 - Temperatura e tempo de queima de cada camada de porcelana, recomendados pelos fabricantes

\begin{tabular}{|lclll|}
\hline & \multicolumn{3}{c}{ Duceram } & \multicolumn{1}{l|}{ EX-3 } \\
\hline & $\mathrm{T}$ & $/$ tempo & $\mathrm{T}$ & / tempo \\
\hline $1^{\text {a }}$ queima (massa dentina) & $910^{\circ} \mathrm{C}$ & 1 minuto & $930^{\circ} \mathrm{C}$ & 1 minuto \\
\hline $2^{\mathrm{a}}$ queima (massa dentina) & $900^{\circ} \mathrm{C}$ & 1 minuto & $920^{\circ} \mathrm{C}$ & 1 minuto \\
\hline glaze & $890^{\circ} \mathrm{C}$ & 1 minuto & $890^{\circ} \mathrm{C}$ & 1 minuto \\
\hline overglaze & $920^{\circ} \mathrm{C}$ & 1 min $50 \mathrm{seg}$ & $940^{\circ} \mathrm{C}$ & 1 min $50 \mathrm{seg}$ \\
\hline
\end{tabular}


Tabela 4.2 - Resumo dos tratamentos de superfície realizados

\begin{tabular}{|c|l|}
\hline T0 & $\begin{array}{l}\text { glaze, de acordo com a temperatura recomendada pelo fabricante; sem e com saliva } \\
\text { na superfície }\end{array}$ \\
\hline T1 & $\begin{array}{l}\text { desgaste com pedra montada Dura-Green formato 31-PC2 (Shofu, Japão), sem e com } \\
\text { saliva na superfície }\end{array}$ \\
\hline T2 & $\begin{array}{l}\text { desgaste com pedra montada Dura-Green e polimento da superfície com roda de } \\
\text { carbureto de silício mais ponta de silicone e pasta diamantada Crystar Past (Kota Ind. } \\
\text { E Com. Ltda., Brasil) aplicada com discos de feltro, sem e com saliva na superfície }\end{array}$ \\
\hline T3 & $\begin{array}{l}\text { overglaze: aumento no tempo de permanência (1 minuto e 50 segundos) e da } \\
\text { temperatura final de glaze, com resultante aumento do escoamento da superfície, sem } \\
\text { e com saliva }\end{array}$ \\
\end{tabular}

\section{Medição de cor}

As medições de cor foram feitas utilizando-se um espectrofotômetro digital intraoral Easyshade, nº de série 602352 (Vita, Alemanha), de duas formas, sem saliva (Grupo A) e com saliva (Grupo B) (Figuras 4.3 e 4.4). Foi utilizada a saliva artificial à base de carmelose sódica, Salivan® (Aspen, Brasil) como substituto à saliva natural. A saliva artificial foi pincelada sobre a superfície dos corpos de prova.

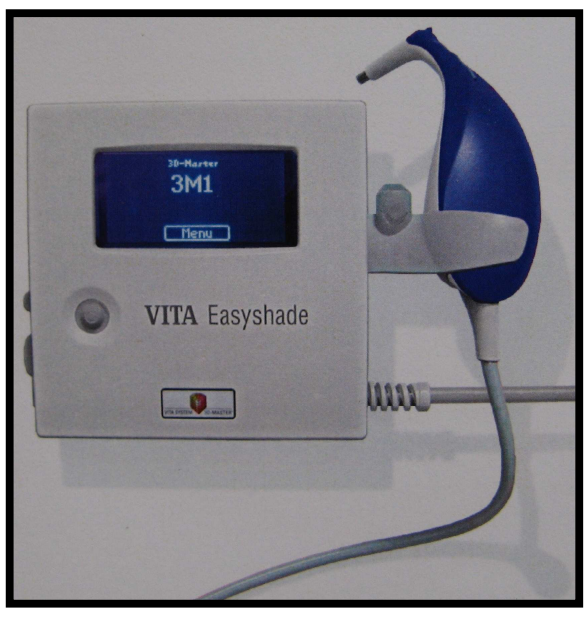

Figura 4.3 - Espectrofotômetro Easyshade

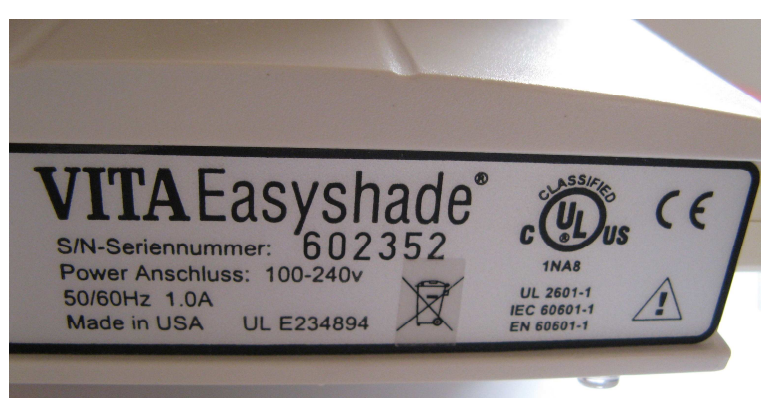

Figura 4.4 - Aparelho utilizado 
Para efetuar medições exatas com o Easyshade, a extremidade da sonda foi posicionada verticalmente em relação à superfície do corpo de prova de modo a não perder o contato com a mesma (Figuras 4.5 e 4.6)

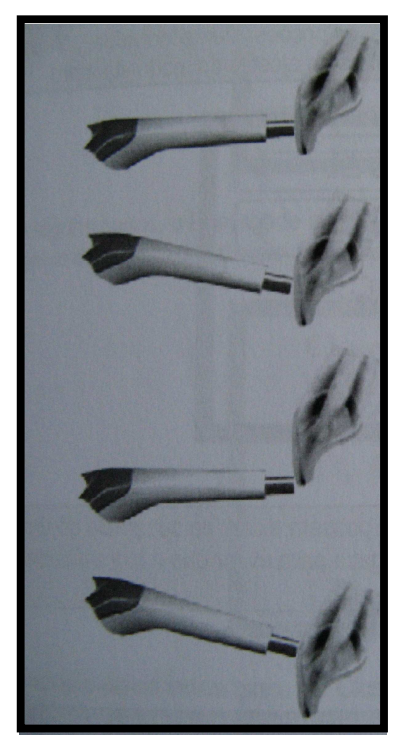

Figura 4.5 - Orientações sobre o posicionamento da sonda do espectrofotômetro; a primeira posição é a correta, as demais são incorretas e levam a uma falha da leitura de cor da superfície.

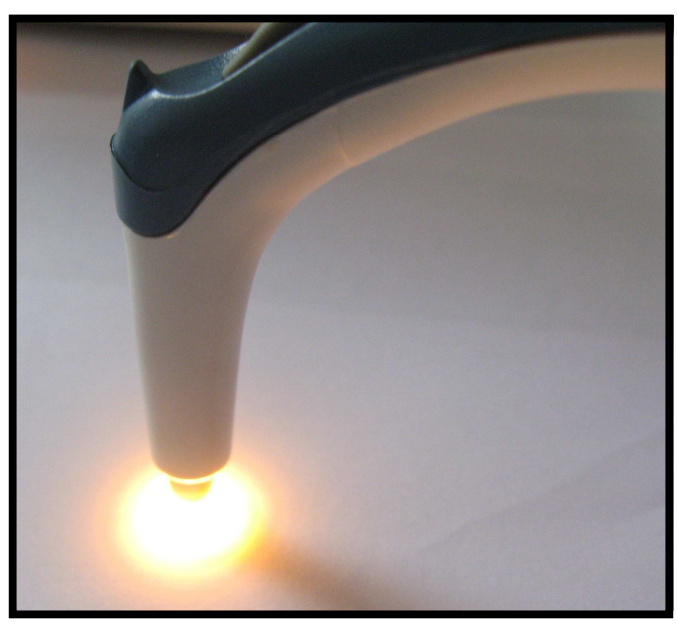

Figura 4.6 - Posicionamento correto da sonda do espectrofotômetro sobre o corpo de prova 
Conforme especificações do aparelho, as curvas de reflectância, no intervalo de comprimentos de onda entre 380 e $780 \mathrm{~nm}$, foram obtidas. As coordenadas de cromaticidade do espaço de cor CIELab são calculadas para estas curvas de reflectâncias, considerando um observador padrão de 2ำ e iluminante D65 padrão, já definidos pelo aparelho. Os valores de luminosidade $L$, matiz e saturação nos eixos $a^{*}$ (vermelho-verde) e $b^{\star}$ (amarelo-azul) foram obtidos. Também foi obtida a leitura de cor das duas escalas mais usualmente utilizadas para escolha de cor dental, a escala Vita Classical (Vita, Alemanha) e a escala 3D-Master, (Vita, Alemanha) (Figuras 4.7 e 4.8$)$.

A cor no momento após o glaze, T0, foi considerado como a cor de referência, e os valores da diferença de cor para cada tratamento foram obtidos utilizando-se a fórmula:

$$
\Delta \mathrm{E}=[(\Delta \mathrm{L}) 2+(\Delta \mathrm{a}) 2+(\Delta \mathrm{b}) 2] 1 / 2
$$

onde , $\Delta \mathrm{E}$ é a diferença total de cor, $\Delta \mathrm{L}$ a diferença total de luminosidade, $\Delta \mathrm{a}$ e $\Delta \mathrm{b}$ as diferenças totais de cromaticidade nos respectivos eixos (vermelho/verde e amarelo/azul). De acordo com as normas CIELab de 1968, $\Delta \mathrm{E}=1$ é a menor diferença de cor percebida por um observador treinado, e $\Delta \mathrm{E} \leq 3$ são diferenças aceitáveis.

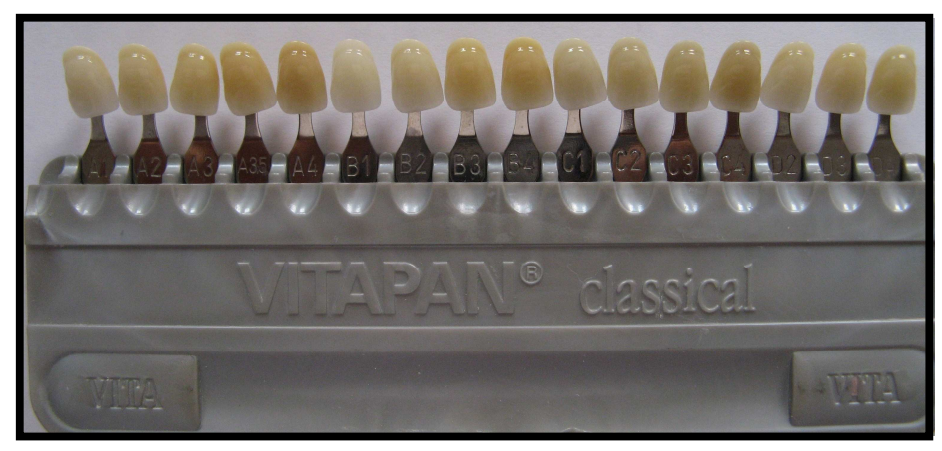

Figura 4.7 - Escala Vitapan Classical 


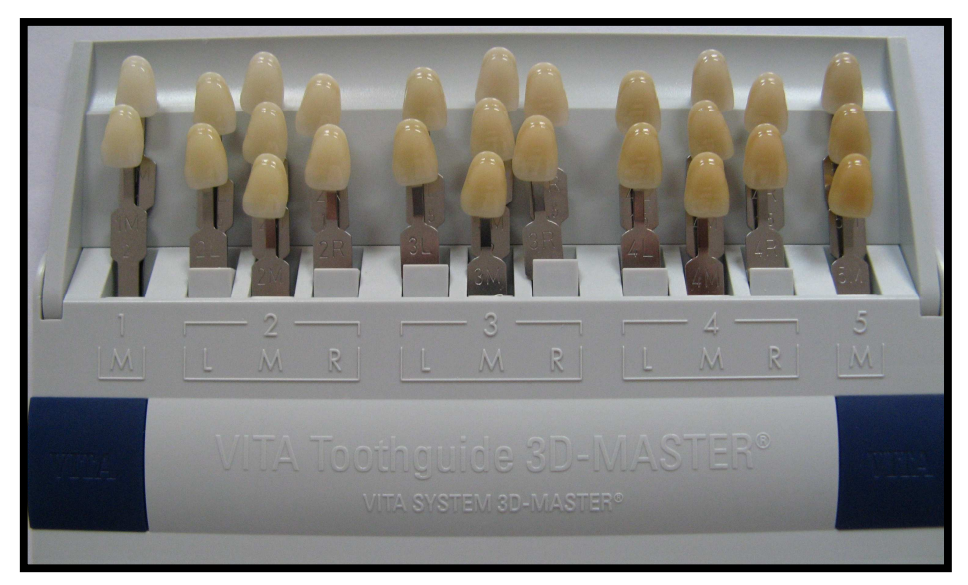

Figura 4.8 - Escala Vita 3D-Master

Análise estatística

A comparação dos grupos experimentais foi feita utilizando-se uma análise descritiva, através de intervalos de confiança de 95\%, e não através de testes de hipótese, pois as variâncias não eram equivalentes para todos os grupos (Tabela 6.1). Para entender a equivalência de procedimentos por intervalos de confiança e por testes de hipótese pode-se sugerir a leitura de Maindonald e Braun (2007) e Bussab e Morettin (2002).

Descreve-se a vantagem desse método como sendo a facilidade de visualização dos diferentes grupos em um mesmo gráfico, conforme os que se apresentam a seguir.

Antes da análise dos dados propriamente dita, seguem algumas pequenas considerações. A primeira delas diz respeito a como o aparelho Easyshade apresenta os dados da leitura de cor na escala Vita Classical. Ele pode determinar a cor do espécime com uma, duas ou três cores. A explicação disto é que se ele identificar uma cor certa aparecerá no visor apenas uma cor, por exemplo, A3,5. Entretanto, se a cor identificada não corresponder a uma cor certa aparecerá duas 
ou até três cores no visor, como por exemplo, A3,5 / A4 / B4. Isto quer dizer que, segundo o próprio fabricante, a cor mais próxima para o objeto medido é a $A 3,5$ porém que sua luminosidade se situa entre a cor escolhida (a primeira apresentada) e as demais cores descritas.

$\mathrm{Na}$ tentativa de se caracterizar de forma mais uniforme as mudanças ocorridas na cor segundo as escalas Classical e 3D Master, uma graduação de escores foi padronizada, aplicada às duas escalas e ilustrada através de graduações de cores nas tabelas como apresentado a seguir:
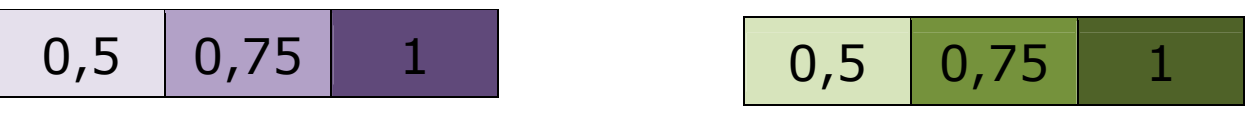

$\mathrm{Na}$ escala Classical, qualquer leitura de cor que não mostrasse alteração alguma foi determinada como 0; a leitura que mantivesse a primeira cor sem alteração e apresentasse alteração de luminosidade (segunda cor medida pelo aparelho) foi padronizada como 0,5 ; alteração da cor primária e manutenção da luminosidade foi determinada como 0,75; e alteração tanto na cor principal como na luminosidade foi dita 1.

Na escala 3D Master, a qual possui três parâmetros representativos do nome da cor, a saber, luminosidade, matiz e saturação, quando não houve alteração em nenhum dos parâmetros foi determinado escore 0 ; qualquer alteração em apenas um parâmetro, não importando qual, foi dita 0,5; alterações em dois parâmetros foi dita 0,75; alteração nos três parâmetros foi determinada como escore 1 .

Em nenhuma das escalas foi determinado o escore 0,25 visto que seria impossível identificar o peso ou a importância do parâmetro alterado. 
Outro detalhe importante a se registrar é que pelo sistema Vita 3D Master os grupos de luminosidade vão de 1 (o mais claro) a 5 ( o mais escuro), as letras representam o matiz L (tonalidade amarelada), M (neutro) e R (avermelhada) e o segundo número que representa a saturação vai de 1 a 3 . Sendo assim, quando temos um número maior para a luminosidade pela escala 3D Master, significa que 0 objeto medido ficou mais escuro, ou seja, que o valor da coordenada $L^{*}$ do sistema CIELab diminuiu. É importante sua atenção neste fato, pois poderia não haver entendimento futuro. 


\section{RESULTADOS}

\subsection{Porcelana Noritake}

A análise da leitura de cor sob o aspecto da escala Vita Classical mostrou que para a porcelana Noritake entre os diferentes tratamentos, ocorreu alguma oscilação na luminosidade da cor, com poucas alterações em número e intensidade dos corpos de prova (Tabelas 5.1, 5.6 e 5.7). Entretanto, entre os grupos A e B, nos grupos com saliva pode-se dizer que as amostras Noritake ficaram mais saturadas, com alterações mais evidentes e numerosas, alterando-se a cor de A3 para A3,5 (Tabelas 5.1 à 5.5).

Tabela 5.1 - Dados da leitura de cor pela escala Classical para a porcelana Noritake

\begin{tabular}{|c|c|c|c|c|c|c|}
\hline & Noritake & & & & & \\
\hline & & 1 & 2 & 3 & 4 & 5 \\
\hline TO & $\begin{array}{c}\text { Grupo } \\
\text { A }\end{array}$ & A3 & A3/A3,5 & A3/A3,5 & A3/A3,5 & A3 \\
\hline & Grupo B & $\mathrm{A} 3 / \mathrm{A} 3,5$ & $\mathrm{~A} 3,5 / \mathrm{A} 3$ & $\mathrm{~A} 3,5 / \mathrm{A} 3$ & A3,5/A3 & $\mathrm{A} 3,5 / \mathrm{A} 3$ \\
\hline & & 0,5 & 1 & 1 & 1 & 0,75 \\
\hline $\mathrm{Tl}$ & $\begin{array}{c}\text { Grupo } \\
\text { A }\end{array}$ & A3 & A3 & A3 & A3 & A3/A3,5 \\
\hline & Grupo B & $\mathrm{A} 3,5 / \mathrm{A} 3$ & $\mathrm{~A} 3 / \mathrm{A} 3,5$ & $\mathrm{~A} 3 / \mathrm{A} 3,5$ & A3/A3,5 & $\mathrm{A} 3 / \mathrm{A} 3,5$ \\
\hline & & 0,75 & 0,5 & 0,5 & 0,5 & 0 \\
\hline $\mathrm{T} 2$ & $\begin{array}{c}\text { Grupo } \\
\text { A }\end{array}$ & $\mathrm{A} 3 / \mathrm{A} 3,5$ & $\mathrm{~A} 3 / \mathrm{A} 3,5$ & $\mathrm{~A} 3 / \mathrm{A} 3,5$ & $\mathrm{~A} 3 / \mathrm{A} 3,5$ & $\mathrm{~A} 3$ \\
\hline & Grupo B & $\mathrm{A} 3,5$ & $\mathrm{~A} 3,5 / \mathrm{C} 3 / \mathrm{A} 4$ & $\mathrm{~A} 3,5 / \mathrm{A} 3$ & $\mathrm{~A} 3,5 / \mathrm{A} 3$ & $\mathrm{~A} 3,5 / \mathrm{A} 3$ \\
\hline & & 0,75 & 1 & 1 & 1 & 0,75 \\
\hline T3 & $\begin{array}{c}\text { Grupo } \\
\text { A }\end{array}$ & A3 & A3 & $\mathrm{A} 3 / \mathrm{A} 3,5$ & $\mathrm{~A} 3 / \mathrm{A} 3,5$ & $\mathrm{~A} 3 / \mathrm{A} 3,5$ \\
\hline & Grupo B & A3/A3,5 & $\mathrm{A} 3,5 / \mathrm{A} 3$ & $\mathrm{~A} 3,5 / \mathrm{C} 3 / \mathrm{A} 4$ & A3/A3,5 & $\mathrm{A} 3,5 / \mathrm{A} 3 / \mathrm{C} 2$ \\
\hline & & 0,5 & 0,75 & 1 & 0 & 1 \\
\hline
\end{tabular}


Tabela 5.2 - Alterações da porcelana Noritake observadas na escala Classical com a presença de saliva em T0 (controle)

\begin{tabular}{c|c|c|c|}
\hline \multirow{2}{*}{ Sem Saliva } & \multicolumn{3}{c|}{ Com saliva } \\
\cline { 2 - 4 } & A3,5/A3 & $A 3 / A 3,5$ & Total \\
\hline A3 & 1 & 1 & 2 \\
\hline A3/A3,5 & 3 & 0 & 3 \\
\hline Total & 4 & 1 & 5 \\
\hline
\end{tabular}

Tabela 5.3 - Alterações da porcelana Noritake observadas na escala Classical com a presença de saliva em T1 (Dura-Green)

\begin{tabular}{|c|c|c|c|}
\hline \multirow{2}{*}{ Sem Saliva } & \multicolumn{3}{|c|}{ Com Saliva } \\
\hline & $A 3,5 / A 3$ & $\mathrm{~A} 3 / \mathrm{A} 3,5$ & Total \\
\hline A3 & 1 & 3 & 4 \\
\hline $\mathrm{A} 3 / \mathrm{A} 3,5$ & 0 & 1 & 1 \\
\hline Total & 1 & 4 & 5 \\
\hline
\end{tabular}

Tabela 5.4 - Alterações da porcelana Noritake observadas na escala Classical com a presença de saliva em T2 (glazeamento a frio)

\begin{tabular}{c|c|c|c|c|}
\hline \multirow{2}{*}{ Sem Saliva } & \multicolumn{5}{c}{ Com Saliva } \\
\cline { 2 - 5 } & $A 3,5$ & $A 3,5 / A 3$ & $A 3,5 / C 3 / A 4$ & Total \\
\hline A3 & 0 & 1 & 0 & 1 \\
\hline A3/A3,5 & 1 & 2 & 1 & 4 \\
\hline Total & 1 & 3 & 1 & 5 \\
\hline
\end{tabular}

Tabela 5.5 - Alterações da porcelana Noritake observadas na escala Classical com

\begin{tabular}{ccc|c|c|c|}
\hline \multirow{2}{*}{$\begin{array}{c}\text { Sem } \\
\text { Saliva }\end{array}$} & \multicolumn{5}{c}{ Com Saliva } \\
\cline { 2 - 6 } & $A 3,5 / A 3$ & $A 3,5 / A 3 / C 2$ & $A 3,5 / C 3 / A 4$ & $A 3 / A 3,5$ & Total \\
\hline A3 & 1 & 0 & 0 & 1 & 2 \\
\hline A3/A3,5 & 0 & 1 & 1 & 1 & 3 \\
\hline Total & 1 & 1 & 1 & 2 & 5 \\
\hline
\end{tabular}


Tabela 5.6 - Alterações da porcelana Noritake observadas na escala Classical sem saliva quanto ao tratamentos

\begin{tabular}{|c|c|c|c|}
\hline \multirow{2}{*}{ Controle } & \multicolumn{3}{c}{ Duragreen } \\
\cline { 2 - 4 } & A3 & A3/A3,5 & Total \\
\hline A3 & 1 & 1 & 2 \\
\hline A3/A3,5 & 3 & 0 & 3 \\
\hline Total & 4 & 1 & 5 \\
\hline Controle & \multicolumn{3}{|c|}{ Glazeamento a frio } \\
\cline { 2 - 4 } & A3 & A3/A3,5 & Total \\
\hline A3 & 1 & 1 & 2 \\
\hline A3/A3,5 & 0 & 3 & 3 \\
\hline Total & 1 & 4 & 5 \\
\hline Controle & \multicolumn{3}{|c|}{ Overglaze } \\
\hline A3 & 1 & A3/A3,5 & Total \\
\hline A3/A3,5 & 1 & 1 & 2 \\
\hline Total & 2 & 2 & 3 \\
\hline
\end{tabular}

Tabela 5.7 - Alterações da porcelana Noritake observadas na escala Classical com saliva quanto aos tratamentos

\begin{tabular}{|c|c|c|c|}
\hline \multirow{2}{*}{ Controle } & \multicolumn{3}{|c|}{ Duragreen } \\
\hline & A3,5/A4 & $\mathrm{B} 4 / \mathrm{A} 3,5$ & Total \\
\hline $\mathrm{A} 3,5$ & 1 & 0 & 1 \\
\hline$A 3,5 / A 4$ & 1 & 3 & 4 \\
\hline Total & 2 & 3 & 5 \\
\hline \multirow{2}{*}{ Controle } & \multicolumn{2}{|c|}{ Glazeamento a frio } & \\
\hline & $A 3,5 / A 4$ & Total & \\
\hline$A 3,5$ & 1 & 1 & \\
\hline$A 3,5 / A 4$ & 4 & 4 & \\
\hline Total & 5 & 5 & \\
\hline \multirow{2}{*}{ Controle } & \multicolumn{3}{|c|}{ Overglaze } \\
\hline & A3,5/A4 & $\mathrm{A} 3,5 / \mathrm{A} 4 / \mathrm{B} 4$ & Total \\
\hline$A 3,5$ & 0 & 1 & 1 \\
\hline$A 3,5 / A 4$ & 1 & 3 & 4 \\
\hline Total & 1 & 4 & 5 \\
\hline
\end{tabular}


A análise da leitura de cor pela escala 3D-Master mostrou que a porcelana Noritake evidenciou alguma oscilação, ora de saturação, ora de luminosidade dos corpos de prova (Tabelas 5.8, 5.13 e 5.14), tais alterações são pouco numerosas e suaves. Porém, comparando-se os grupos $A$ e $B$, em todos os tratamentos observou-se alteração da cor em seus três parâmetros, matiz, saturação e luminosidade, tornando as amostras mais vermelhas na presença de saliva (Tabelas 5.8 à 5.12)

Tabela 5.8 - Dados da leitura de cor pela escala 3D Master para a porcelana Noritake

\begin{tabular}{|c|c|c|c|c|c|c|}
\hline & Noritake & & & & & \\
\hline & & 1 & 2 & 3 & 4 & 5 \\
\hline \multirow[t]{3}{*}{ TO } & $\begin{array}{c}\text { Grupo } \\
\text { A }\end{array}$ & $2,5 \mathrm{M} 3$ & $2,5 \mathrm{M} 3$ & $2,5 \mathrm{M} 3$ & $3 M 3$ & $2,5 \mathrm{M} 3$ \\
\hline & Grupo B & $3 R 2,5$ & $3,5 \mathrm{R} 2$ & $3 R 2,5$ & $3 R 2,5$ & $3 R 2,5$ \\
\hline & & 1 & 1 & 1 & 0,75 & 1 \\
\hline \multirow[t]{3}{*}{$\mathrm{Tl}$} & $\begin{array}{c}\text { Grupo } \\
\text { A }\end{array}$ & $2,5 \mathrm{M} 3$ & $2,5 \mathrm{M} 3$ & $2,5 \mathrm{M} 3$ & $2,5 \mathrm{M} 3$ & $2,5 \mathrm{M} 3$ \\
\hline & Grupo B & $3,5 R 2,5$ & $3 R 2,5$ & $3 R 2,5$ & $3 R 2,5$ & $3 R 2,5$ \\
\hline & & 1 & 1 & 1 & 1 & 1 \\
\hline \multirow[t]{3}{*}{ T2 } & $\begin{array}{c}\text { Grupo } \\
\text { A }\end{array}$ & $2,5 \mathrm{M} 3$ & $2,5 \mathrm{M} 3$ & $2,5 \mathrm{M} 3$ & $2,5 \mathrm{M} 3$ & $2,5 \mathrm{M} 3$ \\
\hline & Grupo B & $3,5 \mathrm{R} 2$ & $3,5 \mathrm{R} 2$ & $3 R 2,5$ & $3 R 2,5$ & $3 R 2,5$ \\
\hline & & 1 & 1 & 1 & 1 & 1 \\
\hline \multirow[t]{3}{*}{ T3 } & $\begin{array}{c}\text { Grupo } \\
\text { A }\end{array}$ & $2,5 \mathrm{M} 3$ & $2,5 \mathrm{M} 3$ & $2,5 \mathrm{M} 3$ & $2,5 \mathrm{M} 3$ & $2,5 \mathrm{M} 3$ \\
\hline & Grupo B & $3 R 2,5$ & $3 \mathrm{R} 2,5$ & $4 \mathrm{R} 2$ & $3 R 2,5$ & $3 R 2,5$ \\
\hline & & 1 & 1 & 1 & 1 & 1 \\
\hline
\end{tabular}


Tabela 5.9 - Alterações da porcelana Noritake observadas na escala 3D Master com a presença de saliva em T0 (controle)

\begin{tabular}{cccc|}
\hline \multirow{2}{*}{ Sem Saliva } & \multicolumn{3}{c}{ Com Saliva } \\
\cline { 2 - 4 } & $3,5 R 2$ & $3 R 2,5$ & Total \\
\hline $2,5 M 3$ & 1 & 3 & 4 \\
\hline $3 M 3$ & 0 & 1 & 1 \\
\hline Total & 1 & 4 & 5 \\
\hline
\end{tabular}

Tabela 5.10 - Alterações da porcelana Noritake observadas na escala 3D Master com a presença de saliva em T1 (Dura-Green)

\begin{tabular}{|c|c|c|c|}
\hline \multirow{2}{*}{ Sem saliva } & \multicolumn{3}{|c|}{ Com Saliva } \\
\hline & $3,5 \mathrm{R} 2,5$ & $3 R 2,5$ & Total \\
\hline $2,5 \mathrm{M} 3$ & 1 & 4 & 5 \\
\hline Total & 1 & 4 & 5 \\
\hline
\end{tabular}

Tabela 5.11 - Alterações da porcelana Noritake observadas na escala 3D Master com a presença de saliva em T2 (glazeamento a frio)

\begin{tabular}{cccc}
\hline \multirow{2}{*}{ Sem Saliva } & \multicolumn{3}{c}{ Com Saliva } \\
\cline { 2 - 4 } & $3,5 \mathrm{R} 2$ & $3 \mathrm{R} 2,5$ & Total \\
\hline $2,5 \mathrm{M} 3$ & 2 & 3 & 5 \\
\hline Total & 2 & 3 & 5 \\
\hline
\end{tabular}

Tabela 5.12 - Alterações da porcelana Noritake observadas na escala 3D Master com a presença de saliva em T3 (overglaze)

\begin{tabular}{cccc}
\hline \multirow{2}{*}{ Sem Saliva } & \multicolumn{3}{c}{ Com Saliva } \\
\cline { 2 - 4 } & $3 \mathrm{R} 2,5$ & $4 \mathrm{R} 2$ & Total \\
\hline $2,5 \mathrm{M} 3$ & 4 & 1 & 5 \\
\hline Total & 4 & 1 & 5 \\
\hline
\end{tabular}


Tabela 5.13 - Alterações da porcelana Noritake observadas na escala 3D Master sem saliva quanto aos tratamentos

\begin{tabular}{|c|c|c|}
\hline \multirow{2}{*}{ Controle } & \multicolumn{2}{|c|}{ Duragreen } \\
\hline & $2,5 \mathrm{M} 3$ & Total \\
\hline $2,5 \mathrm{M} 3$ & 4 & 4 \\
\hline $3 \mathrm{M3}$ & 1 & 1 \\
\hline Total & 5 & 5 \\
\hline \multirow{2}{*}{ Controle } & \multicolumn{2}{|c|}{ Glazeamento a frio } \\
\hline & $2,5 \mathrm{M} 3$ & Total \\
\hline $2,5 \mathrm{M} 3$ & 4 & 4 \\
\hline $3 M 3$ & 1 & 1 \\
\hline Total & 5 & 5 \\
\hline \multirow{2}{*}{ T0 - Controle } & \multicolumn{2}{|c|}{ T3 - Overglaze } \\
\hline & $2,5 \mathrm{M} 3$ & Total \\
\hline $2,5 \mathrm{M} 3$ & 4 & 4 \\
\hline $3 \mathrm{M3}$ & 1 & 1 \\
\hline Total & 5 & 5 \\
\hline
\end{tabular}

Tabela 5.14 - Alterações da porcelana Noritake observadas na escala 3D Master com saliva quanto aos tratamentos

\begin{tabular}{|c|c|c|c|}
\hline \multirow{2}{*}{ Controle } & \multicolumn{3}{c}{ Duragreen } \\
\cline { 2 - 4 } & $3,5 R 2,5$ & $3 R 2,5$ & Total \\
\hline $3,5 R 2$ & 0 & 1 & 1 \\
\hline $3 R 2,5$ & 1 & 3 & 4 \\
\hline Total & 1 & 4 & 5 \\
\hline \hline & \multicolumn{3}{|c}{ Glazeamento a frio } \\
\hline Controle & $3,5 R 2$ & $3 R 2,5$ & Total \\
\hline $3,5 R 2$ & 1 & 0 & 1 \\
\hline $3 R 2,5$ & 1 & 3 & 4 \\
\hline Total & 2 & 3 & 5 \\
\hline & & Overglaze & \\
\hline Controle & $3 R 2,5$ & $4 R 2$ & Total \\
\hline $3,5 R 2$ & 1 & 0 & 1 \\
\hline $3 R 2,5$ & 3 & 1 & 4 \\
\hline Total & 4 & 1 & 5 \\
\hline
\end{tabular}




\subsection{Porcelana Duceram}

$\mathrm{Na}$ escala Vita Classical, quanto aos tratamentos para a porcelana Duceram, T1 alterou a cor em três corpos de prova do grupo B apenas, ou seja, com saliva, de A3,5 para B4. Quanto aos demais tratamentos, notam-se as alterações da cor como oscilação da luminosidade, observando-se o tom suave dos escores das alterações de cor (Tabelas 5.15, 5.20 e 5.21). Na comparação entre os grupos A e B, notam-se alterações suaves e mais numerosas no grupo $B$, com especial atenção à luminosidade (Tabelas 5.16 à 5.19).

Tabela 5.15 - Dados da leitura de cor pela escala Classical para a porcelana Duceram

\begin{tabular}{|c|c|c|c|c|c|c|}
\hline & Duceram & & & & & \\
\hline & & 1 & 2 & 3 & 4 & 5 \\
\hline T0 & Grupo A & A3,5/A3 & A3,5/A3 & A3,5/A3 & A3,5/A3 & A3,5 \\
\hline & Grupo B & A3,5 & A3,5/A4 & A3,5/A4 & A3,5/A4 & A3,5/A4 \\
\hline & & 0,5 & 0,5 & 0,5 & 0,5 & 0,5 \\
\hline T1 & Grupo A & A3,5 & A3,5 & A3,5 & A3,5 & A3,5 \\
\hline & Grupo B & A3,5/A4 & A3,5/A4 & B4/A3,5 & B4/A3,5 & B4/A3,5 \\
\hline & & 0,5 & 0,5 & 0,75 & 0,75 & 0,75 \\
\hline T2 & Grupo A & A3,5 & A3,5 & A3,5 & A3,5 & A3,5 \\
\hline & Grupo B & A3,5/A4 & A3,5/A4 & A3,5/A4 & A3,5/A4 & A3,5/A4 \\
\hline & & 0,5 & 0,5 & 0,5 & 0,5 & 0,5 \\
\hline T3 & Grupo A & A3,5/A3 & A3,5/A3 & A3,5/A3 & A3,5/A3 & A3,5/A3 \\
\hline & Grupo B & A3,5/A4/B4 & A3,5/A4/B4 & A3,5/A4/B4 & A3,5/A4/B4 & A3,5/A4 \\
\hline & & 0,5 & 0,5 & 0,5 & 0,5 & 0,5 \\
\hline
\end{tabular}


Tabela 5.16 - Alterações da porcelana Duceram observadas na escala Classical com a presença de saliva em T0 (controle)

\begin{tabular}{|c|c|c|c|}
\hline \multirow{2}{*}{ Sem Saliva } & \multicolumn{3}{c|}{ Com Saliva } \\
\cline { 2 - 4 } & A3,5 & A3,5/A4 & Total \\
\hline A3,5 & 0 & 1 & 1 \\
\hline A3,5/A3 & 1 & 3 & 4 \\
\hline Total & 1 & 4 & 5 \\
\hline
\end{tabular}

Tabela 5.17 - Alterações da porcelana Duceram observadas na escala Classical com a presença de saliva em T1 (Dura-Green)

\begin{tabular}{|cccc|}
\hline \multirow{2}{*}{ Sem Saliva } & \multicolumn{3}{c|}{ Com Saliva } \\
\cline { 2 - 4 } & A3,5/A4 & B4/A3,5 & Total \\
\hline A3,5 & 2 & 3 & 5 \\
\hline Total & 2 & 3 & 5 \\
\hline
\end{tabular}

Tabela 5.18 - Alterações da porcelana Duceram observadas na escala Classical com a presença de saliva em T2 (glazeamento a frio)

\begin{tabular}{ccc|}
\hline \multirow{2}{*}{ Sem Saliva } & \multicolumn{2}{c|}{ Com Saliva } \\
\cline { 2 - 3 } & A3,5/A4 & Total \\
\hline A3,5 & 5 & 5 \\
\hline Total & 5 & 5 \\
\hline
\end{tabular}

Tabela 5.19 - Alterações da porcelana Duceram observadas na escala Classical com a presença de saliva em T3 (overglaze)

\begin{tabular}{ccccc|}
\hline \multirow{2}{*}{ Sem Saliva } & \multicolumn{3}{c|}{ Com Saliva } \\
\cline { 2 - 4 } & A3,5/A4 & A3,5/A4/B4 & Total \\
\hline A3,5/A3 & 1 & 4 & 5 \\
\hline Total & 1 & 4 & 5 \\
\hline
\end{tabular}


Tabela 5.20 - Alterações da porcelana Duceram observadas na escala Classical sem saliva quanto aos tratamentos

\begin{tabular}{|c|c|c|}
\hline \multirow{2}{*}{ Controle } & \multicolumn{2}{|c|}{ Duragreen } \\
\cline { 2 - 3 } & $\mathrm{A} 3,5$ & Total \\
\hline A3,5 & 1 & 1 \\
\hline A3,5/A3 & 4 & 4 \\
\hline Total & 5 & 5 \\
\hline Controle & Glazeamento a frio \\
\cline { 2 - 3 } & A3,5 & Total \\
\hline A3,5 & 1 & 1 \\
\hline A3,5/A3 & 4 & 4 \\
\hline Total & 5 & 5 \\
\hline \hline Controle & A3,5/A3 & Total \\
\hline A3,5 & 1 & 1 \\
\hline A3,5/A3 & 4 & 4 \\
\hline Total & 5 & 5 \\
\hline
\end{tabular}

Tabela 5.21 - Alterações da porcelana Duceram observadas na escala Classical com saliva quanto aos tratamentos

\begin{tabular}{|c|c|c|c|}
\hline \multirow{2}{*}{ Controle } & \multicolumn{3}{|c}{ Duragreen } \\
\cline { 2 - 3 } & A3,5/A4 & B4/A3,5 & Total \\
\hline A3,5 & 1 & 0 & 1 \\
\hline A3,5/A4 & 1 & 3 & 4 \\
\hline Total & 2 & 3 & 5 \\
\hline \multirow{2}{*}{ Controle } & Glazeamento a frio & \multirow{2}{*}{} \\
\cline { 2 - 3 } & A3,5/A4 & Total \\
\hline A3,5 & 1 & 1 & \\
\hline A3,5/A4 & 4 & 4 & \\
\hline Total & 5 & 5 & \\
\hline \hline Controle & A3,5/A4 & A3,5/A4/B4 & Total \\
\hline A3,5 & 0 & 1 & 1 \\
\hline A3,5/A4 & 1 & 3 & 4 \\
\hline Total & 1 & 4 & 5 \\
\hline
\end{tabular}


A análise da leitura de cor pela escala 3D-Master mostrou que a porcelana Duceram sofreu poucas e suaves oscilações na luminosidade e saturação, mais intensas no grupo B (Tabelas 5.22, 5.27 e 5.28). Já na comparação entre grupos A e B, pode ser observada que com saliva ocorreu o aumento dos valores de luminosidade, o que implica em um objeto mais escuro e diminuição da saturação, porém sem alteração do matiz (Tabelas 5.22 à 5.26).

Tabela 5.22 - Dados da leitura de cor pela escala 3D Master para a porcelana Duceram

\begin{tabular}{|c|c|c|c|c|c|c|}
\hline & Duceram & & & & & \\
\hline & & 1 & 2 & 3 & 4 & 5 \\
\hline T0 & Grupo A & $3 \mathrm{M} 3$ & $3 \mathrm{M} 3$ & $3 \mathrm{M} 3$ & $3 \mathrm{M} 3$ & $3,5 \mathrm{M} 3$ \\
\hline & Grupo B & $3 \mathrm{M} 3$ & $3,5 \mathrm{M} 2,5$ & $3,5 \mathrm{M} 2,5$ & $3,5 \mathrm{M} 2,5$ & $3,5 \mathrm{M} 2,5$ \\
\hline & & 0 & 0,75 & 0,75 & 0,75 & 0,75 \\
\hline T1 & Grupo A & $3,5 \mathrm{M} 3$ & $3 \mathrm{M} 3$ & $3 \mathrm{M} 3$ & $3 \mathrm{M} 3$ & $3 \mathrm{M} 3$ \\
\hline & Grupo B & $3,5 \mathrm{M} 2,5$ & $3,5 \mathrm{M} 2,5$ & $3 \mathrm{M} 3$ & $3 \mathrm{M} 3$ & $3 \mathrm{M} 3$ \\
\hline & & 0,75 & 0,75 & 0 & 0 & 0 \\
\hline T2 & Grupo A & $3 \mathrm{M} 3$ & $3 \mathrm{M} 3$ & $3 \mathrm{M} 3$ & $3 \mathrm{M} 3$ & $3 \mathrm{M} 3$ \\
\hline & Grupo B & $3,5 \mathrm{M} 2,5$ & $3,5 \mathrm{M} 2,5$ & $3,5 \mathrm{M} 2,5$ & $3,5 \mathrm{M} 2,5$ & $3,5 \mathrm{M} 2,5$ \\
\hline & & 0,75 & 0,75 & 0,75 & 0,75 & 0,75 \\
\hline T3 & Grupo A & $3 \mathrm{M} 3$ & $3 \mathrm{M} 3$ & $3 \mathrm{M} 3$ & $3 \mathrm{M} 3$ & $3 \mathrm{M} 3$ \\
\hline & Grupo B & $3,5 \mathrm{M} 2,5$ & $3,5 \mathrm{M} 2,5$ & $3,5 \mathrm{M} 2,5$ & $3,5 \mathrm{M} 2,5$ & $3,5 \mathrm{R} 2,5$ \\
\hline & & 0,75 & 0,75 & 0,75 & 0,75 & 1 \\
\hline
\end{tabular}


Tabela 5.23 - Alterações da porcelana Duceram observadas na escala 3D Master com a presença de saliva em T0 (controle)

\begin{tabular}{|cccc|}
\hline \multirow{2}{*}{ Sem Saliva } & \multicolumn{3}{c}{ Com saliva } \\
\cline { 2 - 4 } & $3,5 \mathrm{M} 2,5$ & $3 \mathrm{M} 3$ & Total \\
\hline $3,5 \mathrm{M} 3$ & 1 & 0 & 1 \\
\hline $3 \mathrm{M} 3$ & 3 & 1 & 4 \\
\hline Total & 4 & 1 & 5 \\
\hline
\end{tabular}

Tabela 5.24 - Alterações da porcelana Duceram observadas na escala 3D Master com a presença de saliva em T1 (Dura-Green)

\begin{tabular}{cccc}
\hline \multirow{2}{*}{ Sem Saliva } & \multicolumn{3}{c}{ Com saliva } \\
\cline { 2 - 4 } & $3,5 M 2,5$ & $3 M 3$ & Total \\
\hline 3,5M3 & 1 & 0 & 1 \\
3M3 & 1 & 3 & 4 \\
Total & 2 & 3 & 5 \\
\hline
\end{tabular}

Tabela 5.25 - Alterações da porcelana Duceram observadas na escala 3D Master com a presença de saliva em T2 (glazeamento a frio)

\begin{tabular}{ccc}
\hline \multirow{2}{*}{ Sem Saliva } & \multicolumn{2}{c}{ Com Saliva } \\
\cline { 2 - 3 } & $3,5 \mathrm{M} 2,5$ & Total \\
\hline 3 M3 & 5 & 5 \\
\hline Total & 5 & 5 \\
\hline
\end{tabular}

Tabela 5.26 - Alterações da porcelana Duceram observadas na escala 3D Master com a presença de saliva em T3 (overglaze)

\begin{tabular}{ccccc}
\hline \multirow{2}{*}{ Sem Saliva } & \multicolumn{3}{c}{ Com Saliva } \\
\cline { 2 - 4 } & $3,5 \mathrm{M} 2,5$ & $3,5 \mathrm{R} 2,5$ & Total \\
\hline 3M3 & 4 & 1 & 5 \\
\hline Total & 4 & 1 & 5 \\
\hline
\end{tabular}


Tabela 5.27 - Alterações da porcelana Duceram observadas na escala 3D Master sem saliva quanto aos tratamentos

\begin{tabular}{|c|c|c|}
\hline \multirow{2}{*}{ Controle } & \multicolumn{3}{c}{ Duragreen } \\
\cline { 2 - 3 } & $3,5 \mathrm{M} 3$ & $3 \mathrm{M} 3$ \\
\hline $3,5 \mathrm{M} 3$ & 0 & 1 \\
\hline $3 \mathrm{M} 3$ & 1 & 3 \\
\hline Total & 1 & 4 \\
\hline Controle & Glazeamento a frio \\
\hline & $3 \mathrm{M} 3$ & Total \\
\hline $3,5 \mathrm{M} 3$ & 1 & 1 \\
\hline $3 \mathrm{M} 3$ & 4 & 4 \\
\hline Total & 5 & 5 \\
\hline & & Overglaze \\
\hline Controle & $3 \mathrm{M} 3$ & Total \\
\hline $3,5 \mathrm{M} 3$ & 1 & 1 \\
\hline $3 \mathrm{M} 3$ & 4 & 4 \\
\hline Total & 5 & 5 \\
\hline
\end{tabular}

Tabela 5.28 - Alterações da porcelana Duceram observadas na escala 3D Master com saliva quanto aos tratamentos

\begin{tabular}{|c|c|c|c|}
\hline \multirow{2}{*}{ Controle } & \multicolumn{3}{|c|}{ Duragreen } \\
\hline & $3,5 \mathrm{M} 2,5$ & $3 \mathrm{M3}$ & Total \\
\hline $3,5 \mathrm{M} 2,5$ & 1 & 3 & 4 \\
\hline $3 M 3$ & 1 & 0 & 1 \\
\hline Total & 2 & 3 & 5 \\
\hline \multirow{2}{*}{ Controle } & \multicolumn{2}{|c|}{ Glazeamento a frio } & \\
\hline & $3,5 \mathrm{M} 2,5$ & Total & \\
\hline $3,5 \mathrm{M} 2,5$ & 4 & 4 & \\
\hline $3 M 3$ & 1 & 1 & \\
\hline Total & 5 & 5 & \\
\hline \multirow{2}{*}{ Controle } & \multicolumn{3}{|c|}{ Overglaze } \\
\hline & $3,5 \mathrm{M} 2,5$ & $3,5 \mathrm{R} 2,5$ & Total \\
\hline $3,5 \mathrm{M} 2,5$ & 3 & 1 & 4 \\
\hline 3M3 & 1 & 0 & 1 \\
\hline Total & 4 & 1 & 5 \\
\hline
\end{tabular}




\subsection{Luminosidade}

As tabelas 5.29 e 5.30 apresentam os valores de luminosidade obtidos para cada material.

Tabela 5.29 - Valores de $L$ apresentados pela porcelana Noritake

\begin{tabular}{|c|c|c|c|c|c|c|}
\hline & Noritake & & & & & \\
\hline & & 1 & 2 & 3 & 4 & 5 \\
\hline T0 & $\begin{array}{c}\text { Grupo } \\
\text { A }\end{array}$ & 86 & 82,2 & 83,4 & 81,1 & 84,5 \\
\hline & Grupo B & 77,2 & 75,1 & 76,3 & 75,6 & 76,7 \\
\hline T1 & $\begin{array}{c}\text { Grupo } \\
\text { A }\end{array}$ & 83,7 & 83,3 & 83,4 & 84,7 & 84,3 \\
\hline & Grupo B & 76,2 & 77,9 & 77,9 & 78,3 & 78 \\
\hline T2 & $\begin{array}{c}\text { Grupo } \\
\text { A }\end{array}$ & 82,5 & 80,9 & 82,6 & 83,2 & 85,8 \\
\hline & Grupo B & 73,2 & 71,1 & 75,5 & 76,2 & 74,2 \\
\hline T3 & $\begin{array}{c}\text { Grupo } \\
\text { A }\end{array}$ & 84,6 & 82,8 & 81,4 & 83,4 & 81 \\
\hline & Grupo B & 76,4 & 74,6 & 70,7 & 77,1 & 73,4 \\
\hline
\end{tabular}

Tabela 5.30 - Valores de L apresentados pela porcelana Duceram

\begin{tabular}{|c|c|c|c|c|c|c|}
\hline & Duceram & & & & & \\
\hline & & 1 & 2 & 3 & 4 & 5 \\
\hline T0 & Grupo A & 83,4 & 83,2 & 82,6 & 82,4 & 80,8 \\
\hline & Grupo B & 75,5 & 73,7 & 73,2 & 74 & 72,4 \\
\hline T1 & Grupo A & 80,1 & 81,9 & 80,2 & 80 & 81,4 \\
\hline & Grupo B & 73,4 & 74,5 & 75,2 & 74,8 & 74,7 \\
\hline T2 & Grupo A & 82 & 81,5 & 83,4 & 82,5 & 83 \\
\hline & Grupo B & 73,2 & 73,2 & 74,7 & 73,4 & 74,3 \\
\hline T3 & Grupo A & 80,2 & 80,9 & 80,7 & 81,6 & 79,5 \\
\hline & Grupo B & 73,7 & 74,3 & 72,8 & 73,8 & 71,9 \\
\hline
\end{tabular}


A tabela 5.31 apresenta os valores de intervalo de confiança para $L^{*}$ utilizados na análise estatística.

Tabela 5.31 - Intervalos de confiança para L

L NA NB DA $\quad$ DB

Inf0 $\quad 81,71 \quad 75,44 \quad 81,74 \quad 73,02$

Sup0 $85,17 \quad 76,924 \quad 83,22 \quad 74,50$

Inf1 $83,14 \quad 76,916 \quad 79,98 \quad 73,78$

Sup1 $84,62 \quad 78,40 \quad 81,46 \quad 75,26$

Inf2 $81,27 \quad 72,31 \quad 81,74 \quad 73,02$

Sup2 $84,73 \quad 75,77 \quad 83,22 \quad 74,50$

Inf3 $80,91 \quad 72,71 \quad 79,84 \quad 72,56$

Sup3 $84,37 \quad 76,17 \quad 81,32 \quad 74,04$

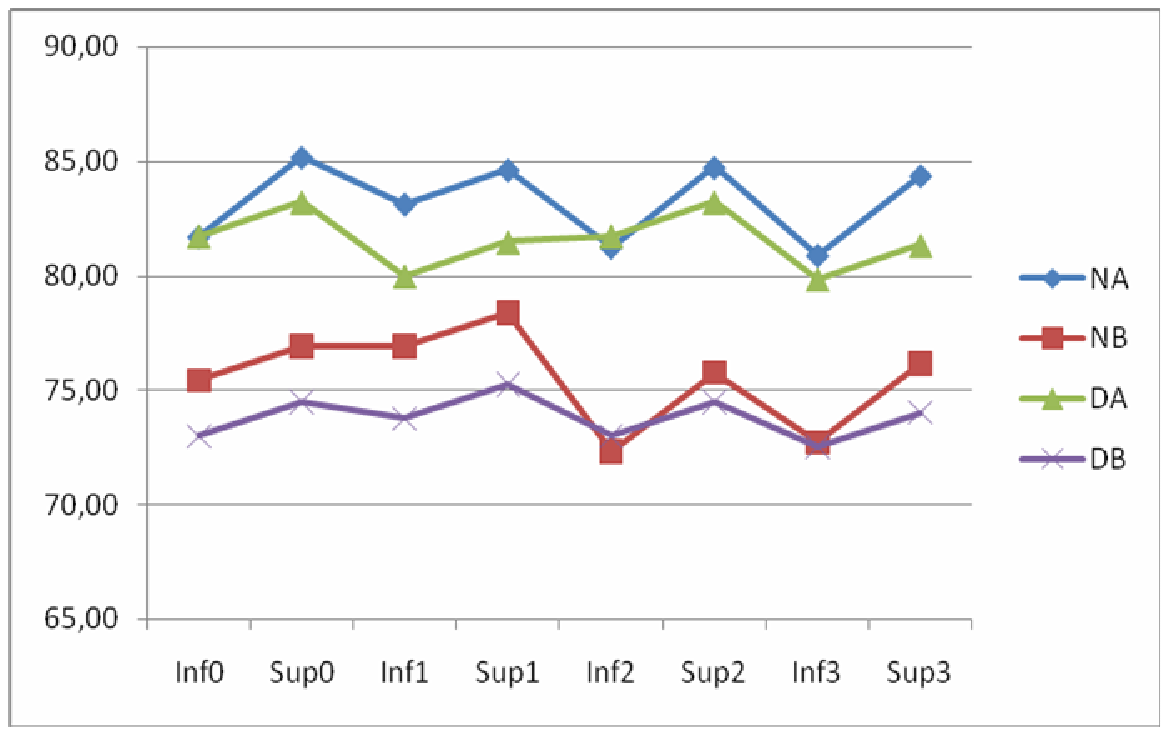

Gráfico 5.1 - Intervalos de confiança para L

Interpretando-se os resultados, pode-se afirmar que a porcelana Noritake não alterou sua luminosidade com nenhum tratamento sem saliva. Porém, com a presença de saliva houve um aumento na luminosidade em $\mathrm{T} 1$, que foi praticamente restabelecida em T2 e T3 ( T0); existe diferença na luminosidade, entretanto a amostra não foi tão grande a ponto de determinar esta diferença, com um nível de significância maior poderíamos identificar tal diferença (Tabela 5.32 e Gráfico 5.1). 
Inversamente, para a porcelana Duceram sem saliva, a luminosidade foi diminuída pelo tratamento $\mathrm{T} 1$, restabelecida pelo tratamento $\mathrm{T} 2$ e novamente diminui em T3. Na presença de saliva, não houve diferença entre nenhum tratamento (Tabela $5.32 \mathrm{e}$ Gráfico 5.1).

Tabela 5.32 - Interpretação da análise estatística dos valores de L para os diferentes tratamentos

\begin{tabular}{|c|c|c|c|}
\hline $\begin{array}{c}\text { NA0 } \\
=\end{array}$ & $\begin{array}{c}\text { NA1 } \\
=\end{array}$ & $\begin{array}{c}\text { NA2 } \\
=\end{array}$ & NA3 \\
\hline NB1 $\sim$ & NB0 $~$ & NB2 $=$ & NB3 \\
\hline DA0 $=$ & DA2 $>$ & DA1 $=$ & DA3 \\
\hline DB0 $=$ & DB1 $=$ & DB2 $=$ & DB3 \\
\hline
\end{tabular}

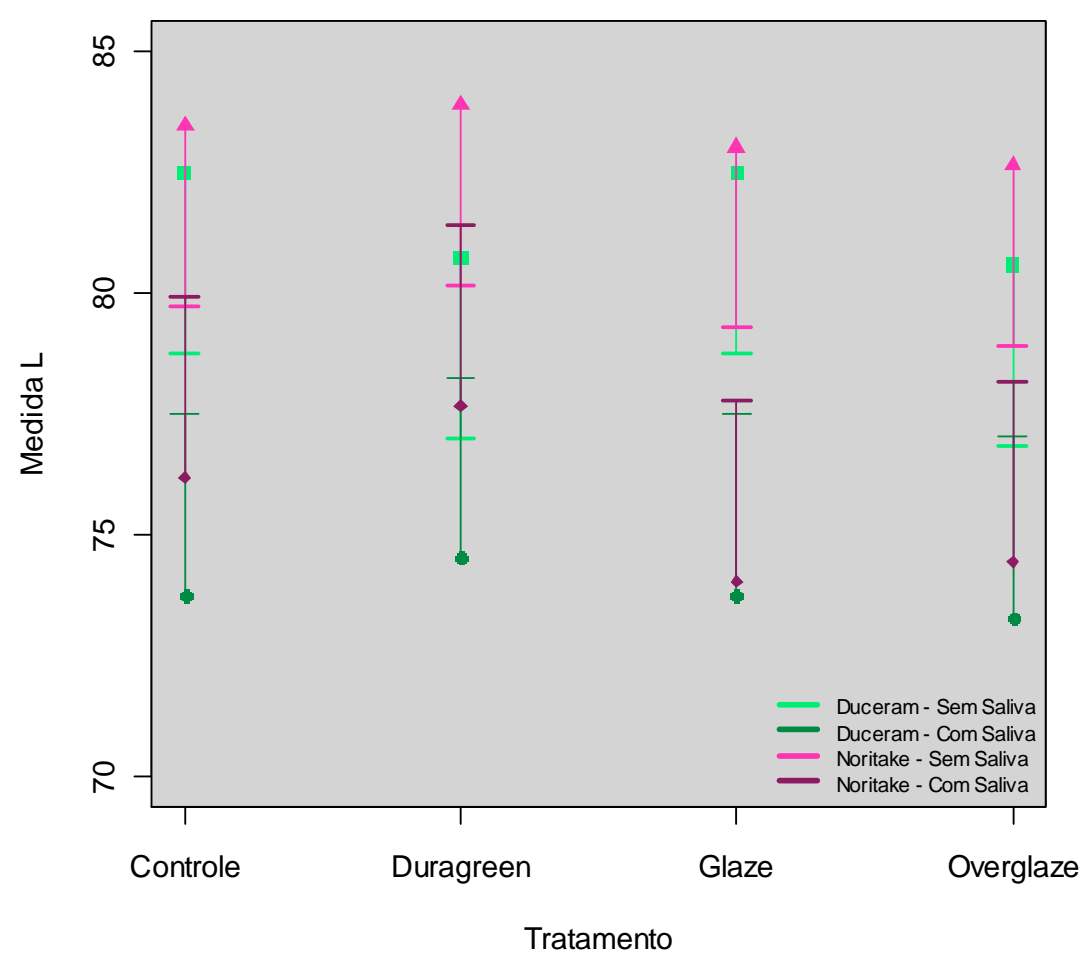

Gráfico 5.2 - Comparação da luminosidade entre tratamentos, marcas e grupos sem e com saliva

$\mathrm{Na}$ comparação entre grupos sem e com saliva, pode-se ainda observar que, em T0 e T1, ocorre diminuição da luminosidade com a presença de saliva; luminosidade esta menor para a porcelana Duceram. Em T2 e T3 também se 
observou a diminuição de $\mathrm{L}$ no grupo com saliva, porém ambas as porcelanas se comportaram igualmente (Tabela 5.33 e Gráficos 5.2 e 5.3).

Tabela 5.33 - Interpretação da análise estatística dos valores de L para os diferentes materiais

\begin{tabular}{|c|l|l|c|}
\hline $\begin{array}{c}\text { NA0 } \\
=\end{array}$ & DA0 $>$ & NB0 $>$ & DB0 \\
\hline $\begin{array}{c}\text { NA1 } \\
>\end{array}$ & DA1 $>$ & NB1 $>$ & DB1 \\
\hline $\begin{array}{c}\text { NA2 } \\
=\end{array}$ & DA2 $>$ & NB2 $=$ & DB2 \\
\hline $\begin{array}{c}\text { NA3 } \\
=\end{array}$ & DA3 $>$ & NB3 $=$ & DB3 \\
\hline
\end{tabular}

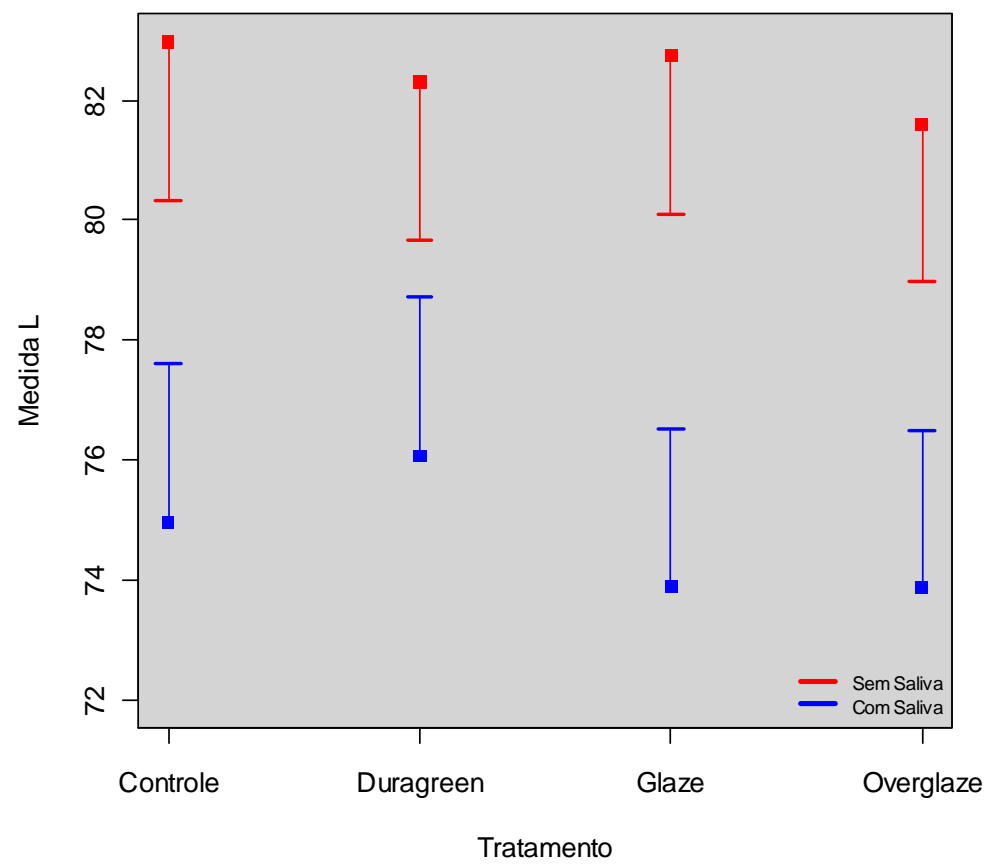

Gráfico 5.3 - Comparação da luminosidade entre os grupos sem e com saliva

\subsection{Coordenada $a^{*}$}

As tabelas 5.34 e 5.35 apresentam os valores de $a^{*}$ obtidos para cada material. 
Tabela 5.34 - Valores de $a^{*}$ apresentados pela porcelana Noritake

\begin{tabular}{|c|c|c|c|c|c|c|}
\hline & Noritake & & & & & \\
\hline & & 1 & 2 & 3 & 4 & 5 \\
\hline T0 & Grupo A & 4,2 & 3,9 & 3,6 & 3,6 & 3,8 \\
\hline & Grupo B & 3,2 & 3 & 2,7 & 2,7 & 3 \\
\hline T1 & Grupo A & 3,8 & 4 & 3,8 & 3,9 & 4,1 \\
\hline & Grupo B & 2,8 & 2,6 & 2,6 & 2,6 & 2,8 \\
\hline T2 & Grupo A & 3,9 & 3,9 & 3,6 & 3,6 & 4 \\
\hline & Grupo B & 3 & 3 & 2,7 & 2,7 & 3 \\
\hline T3 & Grupo A & 3,7 & 3,3 & 4 & 3,4 & 3,3 \\
\hline & Grupo B & 2,8 & 2,5 & 3,1 & 2,3 & 2,5 \\
\hline
\end{tabular}

Tabela 5.35 - Valores de $\mathrm{a}^{*}$ apresentados pela porcelana Duceram

\begin{tabular}{|c|c|c|c|c|c|c|}
\hline & Duceram & & & & & \\
\hline & & 1 & 2 & 3 & 4 & 5 \\
\hline T0 & Grupo A & 2,7 & 3 & 3 & 2,8 & 2,8 \\
\hline & Grupo B & 2,4 & 2,5 & 2,8 & 2,4 & 2,4 \\
\hline T1 & Grupo A & 3,2 & 2,9 & 2,7 & 2,8 & 2,9 \\
\hline & Grupo B & 2,8 & 2,4 & 2,1 & 2,1 & 2,3 \\
\hline T2 & Grupo A & 2,9 & 2,8 & 2,8 & 3 & 2,9 \\
\hline & Grupo B & 2,6 & 2,6 & 2,4 & 2,7 & 2,5 \\
\hline T3 & Grupo A & 2,7 & 2,6 & 2,3 & 2,5 & 2,3 \\
\hline & Grupo B & 2,5 & 2,3 & 2,1 & 2 & 2 \\
\hline
\end{tabular}

A tabela 5.36 apresenta os valores de intervalo de confiança para $a^{\star}$ utilizados na análise estatística.

Tabela 5.36 - Intervalos de confiança para a*

$\begin{array}{ccccc}\text { a } & \text { NA } & \text { NB } & \text { DA } & \text { DB } \\ \text { Inf0 } & 3,61 & 2,712 & 2,75 & 2,292 \\ \text { Sup0 } & 4,03 & 3,13 & 2,97 & 2,708 \\ \text { Inf1 } & 3,81 & 2,57 & 2,692 & 2,13 \\ \text { Sup1 } & 4,03 & 2,79 & 3,11 & 2,55 \\ \text { Inf2 } & 3,59 & 2,77 & 2,77 & 2,45 \\ \text { Sup2 } & 4,01 & 2,99 & 2,99 & 2,67 \\ \text { Inf3 } & 3,33 & 2,43 & 2,27 & 2,07 \\ \text { Sup3 } & 3,75 & 2,85 & 2,688 & 2,290\end{array}$




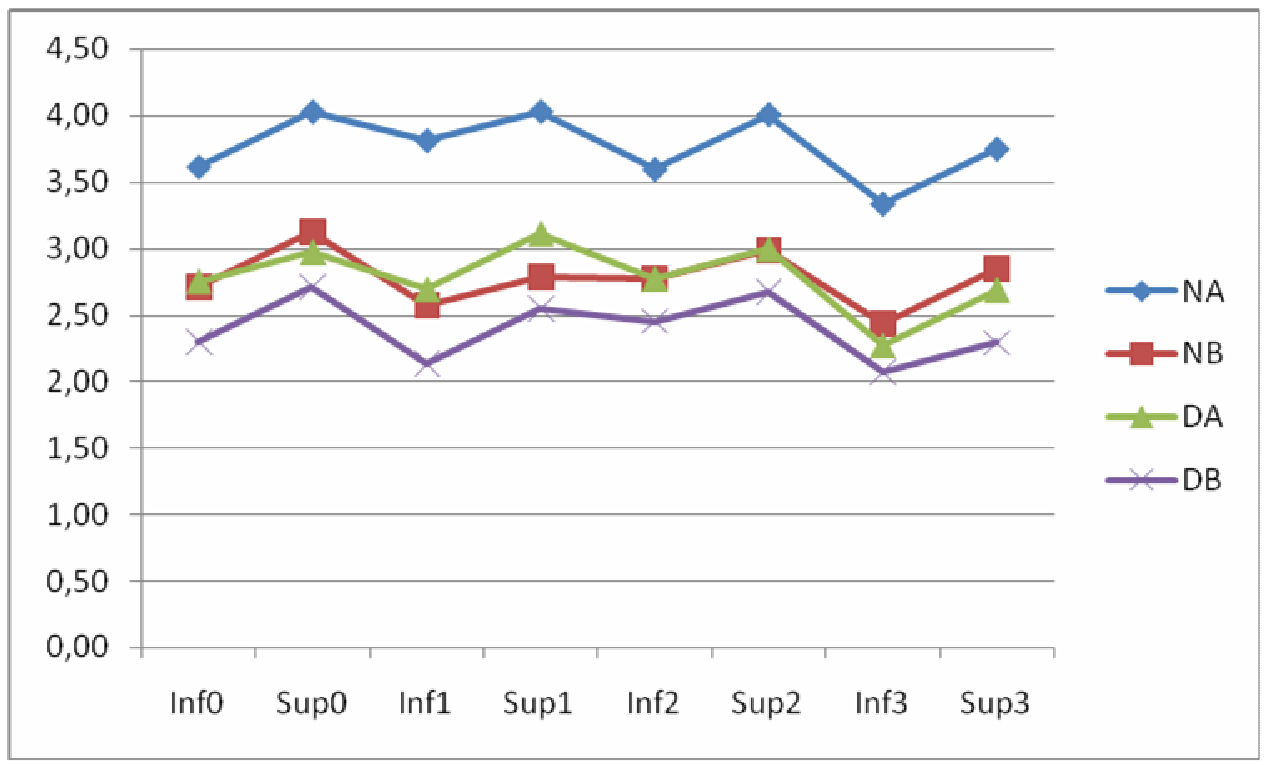

Gráfico 5.4 - Intervalos de confiança para a*

Nesta análise, observamos que nenhum tratamento, tanto no grupo A como em B, alterou a cromaticidade a* para a porcelana Noritake (Tabela 5.37 e Gráfico 5.4). A porcelana Duceram diminuiu o eixo $a^{*}$ com o tratamento 3 , o que mostrou que sem ou com saliva o overglaze foi capaz de deixar o dente menos vermelho (Tabela 5.37 e Gráfico 5.4).

Tabela 5.37 - Interpretação da análise estatística dos valores de $a^{*}$ para os diferentes tratamentos

\begin{tabular}{|l|l|l|l|}
\hline NA0 $=$ & NA1 $=$ & NA2 $=$ & NA3 \\
\hline NB0 $=$ & NB1 $=$ & NB2 $=$ & NB3 \\
\hline DA0 $=$ & DA1 $=$ & DA2 $>$ & DA3 \\
\hline DB0 $=$ & DB1 $=$ & DB2 $>$ & DB3 \\
\hline
\end{tabular}




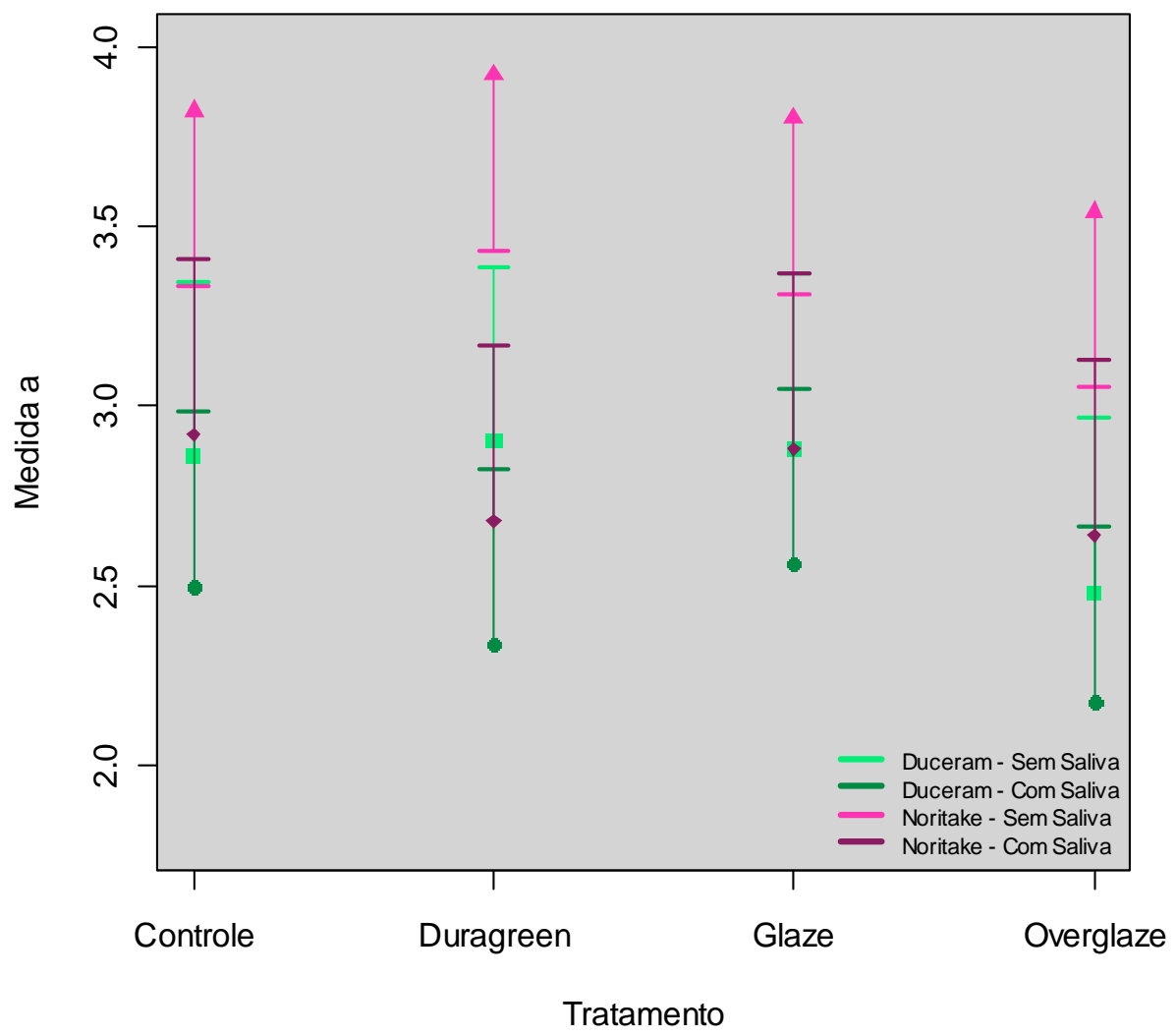

Gráfico 5.5 - Comparação da coordenada $\mathrm{a}^{*}$ entre tratamentos, marcas e grupos sem e com saliva

Na comparação dos grupos sem e com saliva ( $A$ e B), pode se observar que os valores de $a^{*}$ diminuíram com a presença de saliva em ambos os materiais, da mesma maneira, em todos os tratamentos, ou seja, a presença de saliva torna o espécime menos vermelho (Tabela 5.38 e Gráficos 5.5 e 5.6).

Tabela 5.38 - Interpretação da análise estatística dos valores de a* para os diferentes materiais

\begin{tabular}{|l|l|l|l|}
\hline NA0 $>$ & NB0 $=$ & DA0 $>$ & DB0 \\
\hline NA1 $>$ & NB1 $=$ & DA1 $>$ & DB1 \\
\hline NA2 $>$ & NB2 $=$ & DA2 $>$ & DB2 \\
\hline NA3 $>$ & NB3 $=$ & DA3 $>$ & DB3 \\
\hline
\end{tabular}




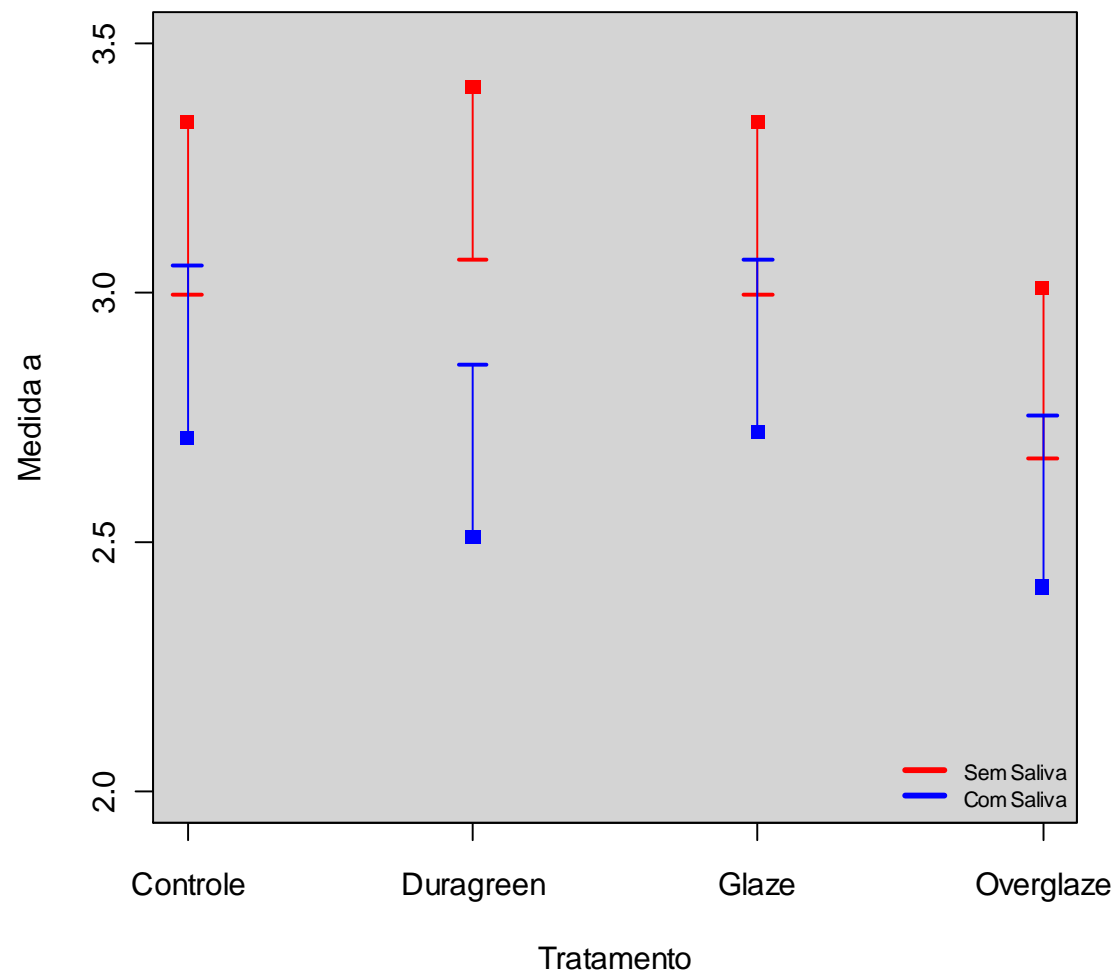

Gráfico 5.6 - Comparação da coordenada a* entre os grupos sem e com saliva

\subsection{Coordenada $b^{*}$}

As tabelas 5.39 e 5.40 apresentam os valores de b* obtidos para cada material. 
Tabela 5.39 - Valores de $b^{*}$ apresentados pela porcelana Noritake

\begin{tabular}{|c|c|c|c|c|c|c|}
\hline & Noritake & & & & & \\
\hline & & 1 & 2 & 3 & 4 & 5 \\
\hline T0 & Grupo A & 32,7 & 30,8 & 32 & 31,2 & 31,6 \\
\hline & Grupo B & 27,2 & 26,1 & 27 & 26,8 & 26,8 \\
\hline T1 & Grupo A & 30,7 & 31,7 & 30,6 & 31,4 & 32,3 \\
\hline & Grupo B & 26,8 & 26,3 & 26,3 & 26,4 & 27,1 \\
\hline T2 & Grupo A & 31,3 & 30,6 & 31,4 & 31,8 & 32,6 \\
\hline & Grupo B & 26,6 & 25,5 & 26,7 & 27,1 & 26,3 \\
\hline T3 & Grupo A & 31,2 & 30,5 & 31 & 31,4 & 29,8 \\
\hline & Grupo B & 25,9 & 25,6 & 25,3 & 26,4 & 25,2 \\
\hline
\end{tabular}

Tabela 5.40 - Valores de $b^{*}$ apresentados pela porcelana Duceram

\begin{tabular}{|c|c|c|c|c|c|c|}
\hline & Duceram & & & & & \\
\hline & & 1 & 2 & 3 & 4 & 5 \\
\hline T0 & Grupo A & 35,2 & 35,5 & 35,5 & 34,7 & 36,5 \\
\hline & Grupo B & 31,4 & 31,2 & 32,5 & 30,9 & 31,8 \\
\hline T1 & Grupo A & 36 & 35,4 & 33,9 & 33,6 & 34,7 \\
\hline & Grupo B & 32 & 31,4 & 30,4 & 30 & 30,8 \\
\hline T2 & Grupo A & 35,3 & 34,4 & 35,7 & 35,2 & 35,5 \\
\hline & Grupo B & 31,3 & 30,8 & 31,5 & 31,5 & 31,4 \\
\hline T3 & Grupo A & 33,9 & 34,2 & 32,9 & 33,2 & 32,2 \\
\hline & Grupo B & 30,1 & 30,6 & 29,2 & 29,4 & 28,1 \\
\hline
\end{tabular}

A tabela 5.41 apresenta os valores de intervalo de confiança para $b^{*}$ utilizados na análise estatística.

Tabela 5.41 - Intervalos de confiança para b*

b NA NB DA DB

Inf0 $\quad 30,99 \quad 26,41 \quad 34,81 \quad 30,89$

Sup0 $\quad 32,33 \quad 27,15 \quad 36,15 \quad 32,23$

Inf1 $30,67 \quad 26,21 \quad 34,05 \quad 30,25$

Sup1 $32,01 \quad 26,95 \quad 35,39 \quad 31,59$

$\begin{array}{lllll}\text { Inf2 } & 30,87 & 25,77 & 34,85 & 30,93\end{array}$

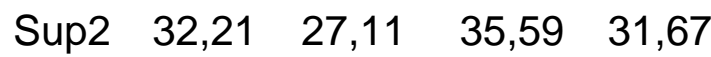

Inf3 $\quad 30,11 \quad 25,31 \quad 32,61 \quad 28,81$

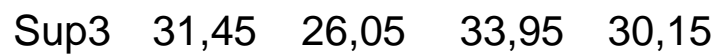




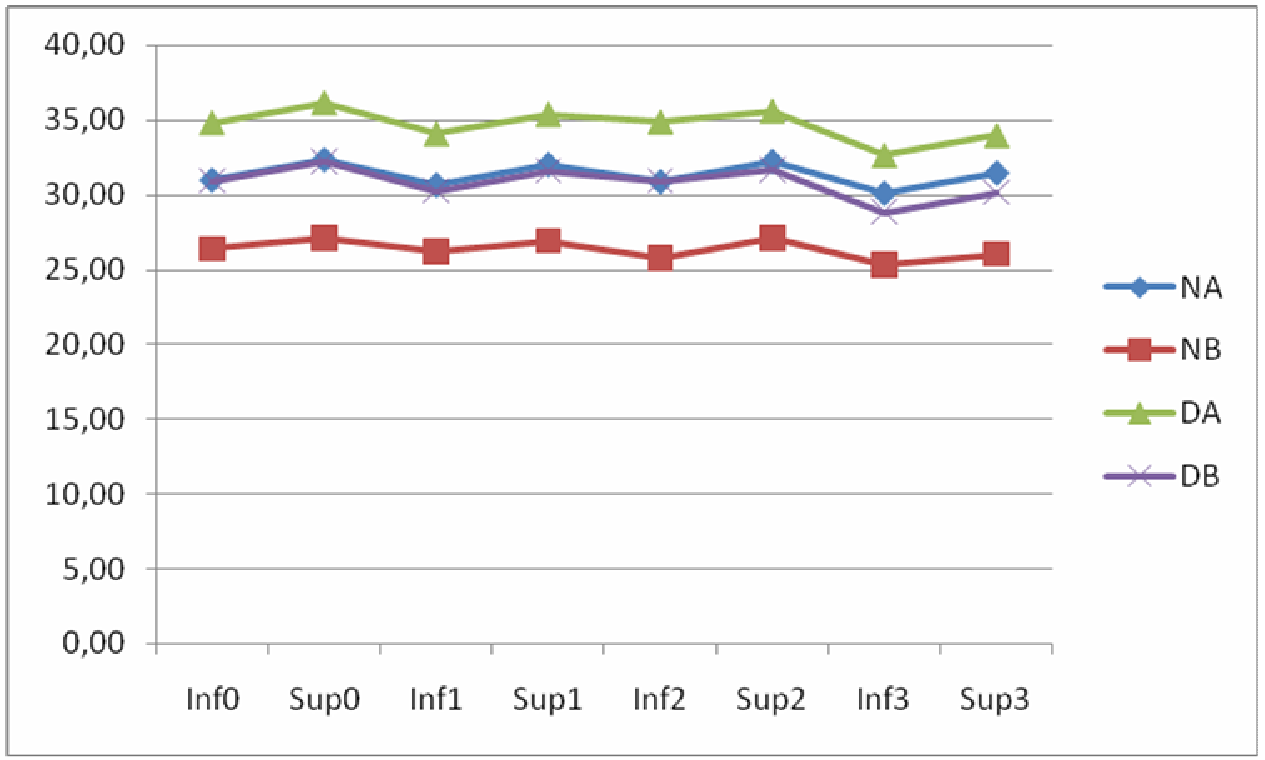

Gráfico 5.7 - Intervalos de confiança para b*

Quanto à cromaticidade em b*, a porcelana Noritake não sofreu alteração com nenhum dos tratamentos realizados (Tabela 5.42 e Gráfico 5.7). A porcelana Duceram teve diminuição dos valores de $b^{*}$ em T3 sem e com saliva, tornando os espécimes menos amarelos (Tabela 5.42 e Gráfico 5.7).

Tabela 5.42 - Interpretação da análise estatística dos valores de b para os diferentes tratamentos

\begin{tabular}{|l|l|l|l|}
\hline NA0 $=$ & NA1 $=$ & NA2 $=$ & NA3 \\
\hline NB0 $=$ & NB1 $=$ & NB2 $=$ & NB3 \\
\hline DA0 $=$ & DA1 $=$ & DA2 $~$ & DA3 \\
\hline DB0 $=$ & DB1 $=$ & DB2 $>$ & DB3 \\
\hline
\end{tabular}




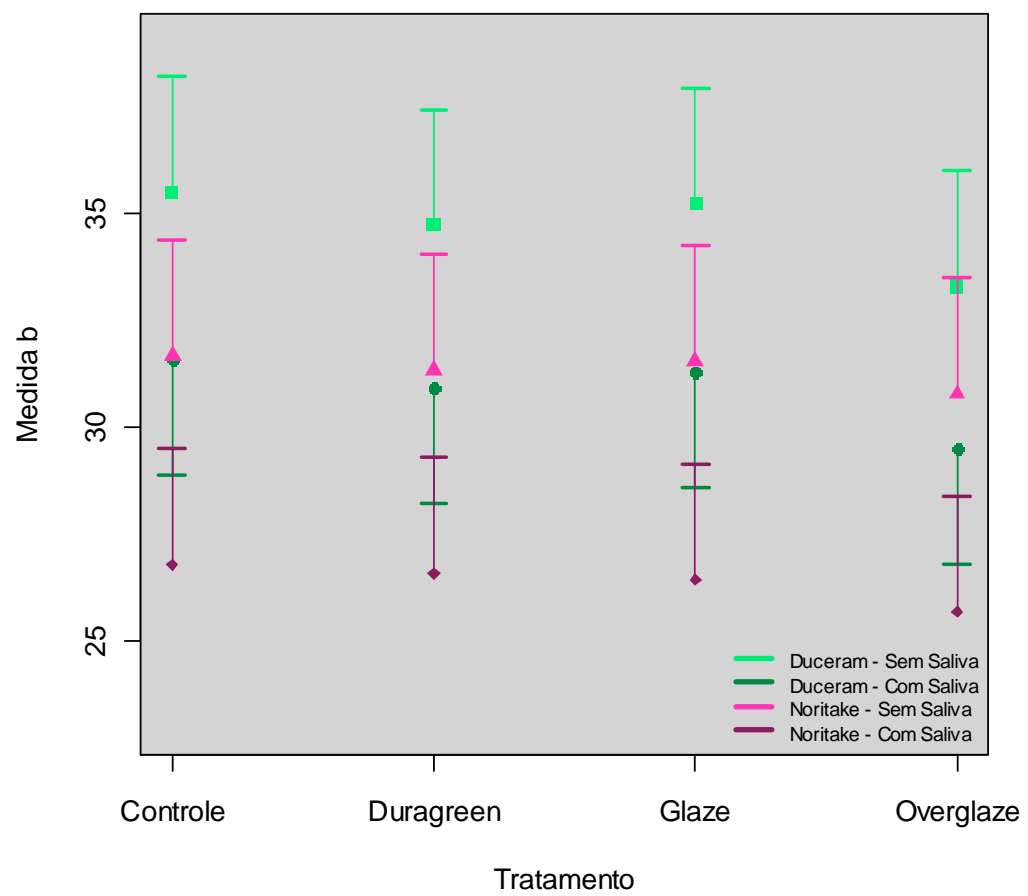

Gráfico 5.8 - Comparação da coordenada $b^{*}$ entre tratamentos, marcas e grupos sem e com saliva

Na comparação entre os grupos sem e com saliva (A e B), os valores de b* diminuíram com a presença de saliva em ambos os materiais, da mesma maneira, em todos os tratamentos, ou seja, a presença de saliva torna o espécime menos amarelo (Tabela 5.43 e Gráficos 5.8 e 5.9).

Tabela 5.43 - Interpretação da análise estatística dos valores de $b^{\star}$ para os diferentes materiais

\begin{tabular}{|l|l|l|l|}
\hline DA0 $>$ & NA0 $=$ & DB0 $>$ & NB0 \\
\hline DA1 $>$ & NA1 $=$ & DB1 $>$ & NB1 \\
\hline DA2 $>$ & NA2 $=$ & DB2 $>$ & NB2 \\
\hline DA3 $>$ & NA3 $~$ & DB3 $>$ & NB3 \\
\hline
\end{tabular}




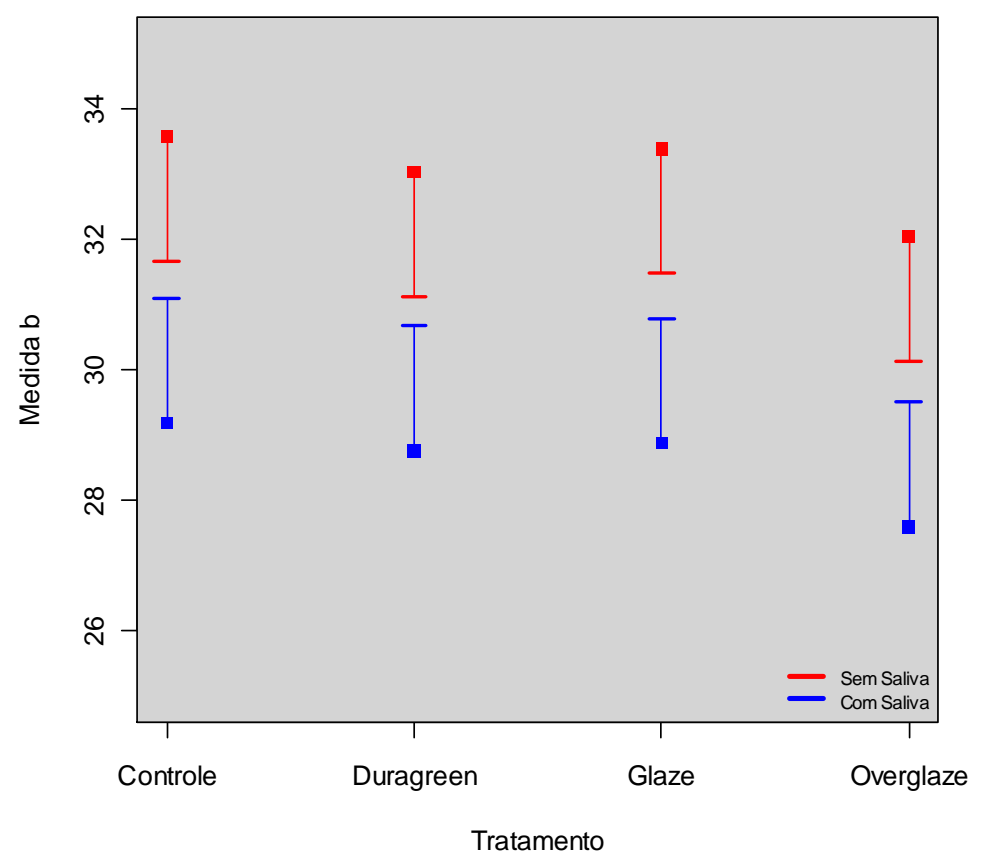

Gráfico 5.9 - Comparação da coordenada b* entre os grupos sem e com saliva

\section{$5.6 \Delta \mathrm{E}$}

Em relação à porcelana Noritake, não houve um aumento do $\Delta \mathrm{E}$, ou seja, da diferença total de cor entre os tratamentos sem saliva e o instante T0, que fosse próximo ou maior do que 3 , valor este considerado como o limite aceitável ao olho humano para a diferença de cor entre dois objetos. O desgaste com a ponta DuraGreen causou um $\Delta \mathrm{E}$ de 0,55 . O glazeamento a frio provocou $\Delta \mathrm{E}$ de 0,45 diminuindo um pouco a diferença de cor. $\mathrm{O}$ overglaze promoveu o maior valor de $\Delta \mathrm{E}, 1,22$, embora este seja um valor considerado aceitável da diferença de cor. Nota-se também que os valores de $\Delta \mathrm{E}$ todos aumentaram na presença de saliva, 1,$51 ; 2,16$ e 2,08 respectivamente, mas ainda permanecendo dentro do nível aceitável (Tabela 5.44). 
Tabela 5.44 - Diferença total de cor entre os valores iniciais e os diferentes tratamentos para a porcelana Noritake sem e com saliva

\begin{tabular}{|c|c|}
\hline Noritake & $\Delta \mathrm{E}$ \\
\hline T0 e 1 A & 0,55 \\
\hline T0 e 2 A & 0,45 \\
\hline T0 e 3 A & 1,22 \\
\hline T0 e 1 B & 1,51 \\
\hline T0 e 2 B & 2,16 \\
\hline T 0 e 3 B & 2,08 \\
\hline
\end{tabular}

Para a porcelana Duceram, os valores de $\Delta \mathrm{E}$ também permaneceram abaixo do valor limite considerado diferença de cor aceitável, contudo vale ressaltar que, de modo geral, foram encontrados valores maiores que os da porcelana Noritake no grupo sem saliva. No grupo A temos 1,92; 1,03 e 2,93 respectivamente, e no grupo B 1,01, 1,03 e 2,15. Nota-se também que os valores de $\Delta \mathrm{E}$ em T1 e T3 diminuíram na presença de saliva e em T2 permaneceu estável (Tabela 5.45).

O tratamento T3 foi o que provocou as maiores diferenças de cor com e sem saliva em ambos os materiais, chegando próximo ao valor limite (Gráfico 5.10).

Tabela 5.45 - Diferença total de cor entre os valores iniciais e os diferentes tratamentos para a porcelana Duceram sem e com saliva

\begin{tabular}{|c|c|}
\hline Duceram & $\Delta \mathrm{E}$ \\
\hline T0 e $1 \mathrm{~A}$ & 1,92 \\
\hline T0 e 2 A & 1,03 \\
\hline T0 e 3 A & 2,93 \\
\hline T0 e 1 B & 1,01 \\
\hline T0 e 2 B & 1,03 \\
\hline T 0 e 3 B & 2,15 \\
\hline
\end{tabular}




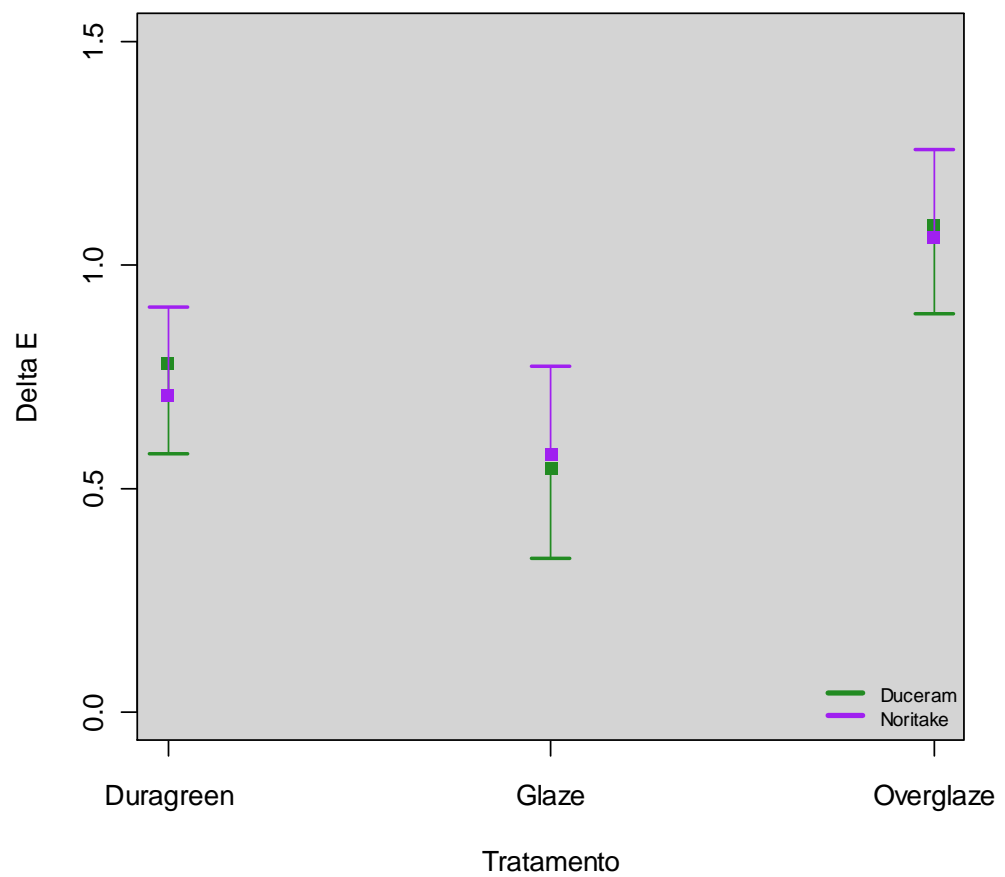

Gráfico 5.10 - Comparação dos valores de $\Delta \mathrm{E}$ para os diferentes tratamentos e materiais 
Tabela 5.46 - Resumo dos resultados (valores médios de L, $a^{*}$ e b*)

\begin{tabular}{|c|c|c|c|c|c|c|}
\hline & $\begin{array}{l}\text { Escala } \\
\text { classical }\end{array}$ & $\begin{array}{c}\text { Escala 3D } \\
\text { Master }\end{array}$ & $a^{*}$ & $b^{*}$ & $L^{*}$ & $\Delta \mathrm{E}$ \\
\hline $\mathrm{N}_{\mathrm{TO}} \mathrm{A}$ & A3/A3,5 & $2,5 \mathrm{M} 3$ & 3,82 & 31,66 & 83,44 & --- \\
\hline $\mathrm{N}_{\mathrm{T} 0} \mathrm{~B}$ & A3,5/A3 & $3 \mathrm{R} 2,5$ & 2,92 & 26,78 & 76,18 & --- \\
\hline $\mathrm{N}_{\mathrm{T} 1} \mathrm{~A}$ & A3 & $2,5 \mathrm{M} 3$ & 3,92 & 31,34 & 83,88 & 0,55 \\
\hline $\mathrm{N}_{\mathrm{T} 1} \mathrm{~B}$ & A3/A3,5 & $3 R 2,5$ & 2,68 & 26,58 & 77,66 & 1,51 \\
\hline $\mathrm{N}_{\mathrm{T} 2} \mathrm{~A}$ & A3/A3,5 & $2,5 \mathrm{M} 3$ & 3,80 & 31,54 & 83,00 & 0,45 \\
\hline $\mathrm{N}_{\mathrm{T} 2} \mathrm{~B}$ & A3,5/A3 & $3 \mathrm{R} 2,5$ & 2,88 & 26,44 & 74,04 & 2,16 \\
\hline $\mathrm{N}_{\mathrm{T} 3} \mathrm{~A}$ & A3/A3,5 & $2,5 \mathrm{M} 3$ & 3,54 & 30,78 & 82,64 & 1,22 \\
\hline $\mathrm{N}_{\mathrm{T} 3} \mathrm{~B}$ & inconclusivo & 3R2,5 & 2,64 & 25,68 & 74,44 & 2,08 \\
\hline $\mathrm{D}_{\text {то }} \mathrm{A}$ & A3,5/A3 & $3 \mathrm{M} 3$ & 2,86 & 35,48 & 82,48 & --- \\
\hline $\mathrm{D}_{\text {T0 }} \mathrm{B}$ & A3,5/A4 & $3,5 \mathrm{M} 2,5$ & 2,50 & 31,56 & 73,76 & --- \\
\hline $\mathrm{D}_{\mathrm{T} 1} \mathrm{~A}$ & $A 3,5$ & 3M3 & 2,90 & 34,72 & 80,72 & 1,92 \\
\hline$D_{T 1} B$ & B4/A3,5 & 3M3 & 2,34 & 30,92 & 74,52 & 1,01 \\
\hline $\mathrm{D}_{\mathrm{T} 2} \mathrm{~A}$ & $A 3,5$ & $3 \mathrm{M} 3$ & 2,88 & 35,22 & 82,48 & 1,03 \\
\hline $\mathrm{D}_{\mathrm{T} 2} \mathrm{~B}$ & A3,5/A4 & $3,5 \mathrm{M} 2,5$ & 2,56 & 31,30 & 73,76 & 1,03 \\
\hline $\mathrm{D}_{\text {т3 }} \mathrm{A}$ & A3,5/A3 & $3 \mathrm{M} 3$ & 2,48 & 33,28 & 80,58 & 2,93 \\
\hline $\mathrm{D}_{\text {T3 }} \mathrm{B}$ & A3,5/A4/B4 & $3,5 \mathrm{M} 2,5$ & 2,18 & 29,48 & 73,30 & 2,15 \\
\hline
\end{tabular}




\section{DISCUSSÃO}

A utilização de um espectrofotômetro para análise de cor oferece as coordenadas de cor L (luminosidade), $a^{*}$ (cromaticidade no eixo a, vermelho-verde, onde $+a$ equivale a vermelho e -a equivale a verde) e $b^{*}$ (cromaticidade no eixo amarelo-azul, onde $+b$ equivale a amarelo e $-b$ equivale a azul), segundo parâmetros de Commission Internationale de L'Eclairage (Figuras 6.1 e 6.2).

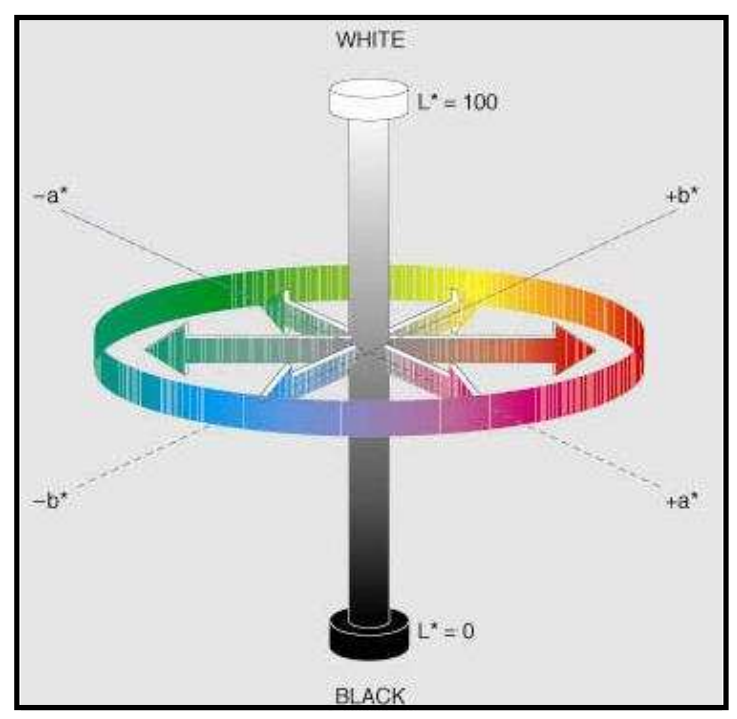

Figura 6.1 - Esquema de cor CIELab

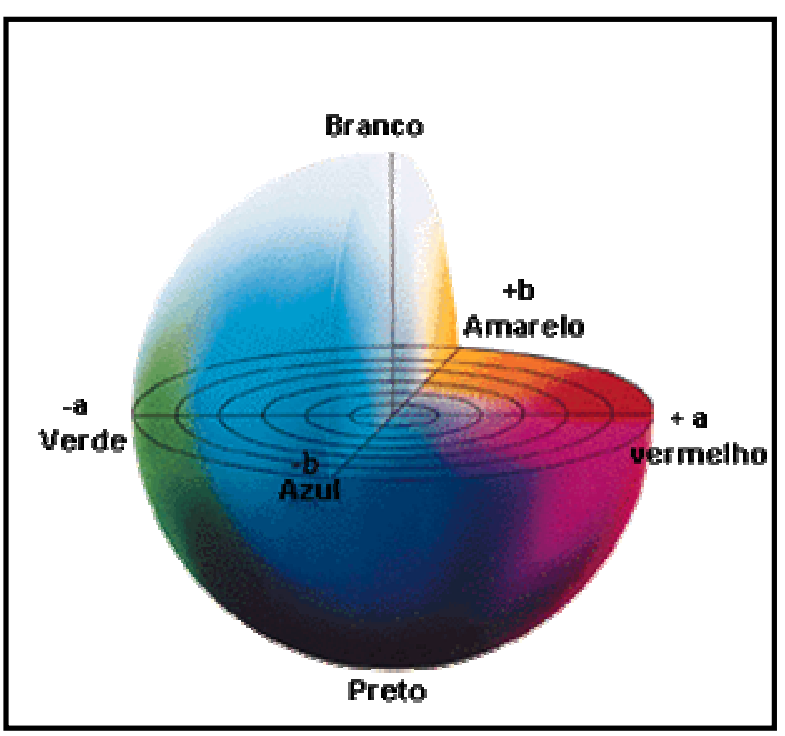

Figura 6.2 - Espaço de cor CIELab 
O aparelho utilizado neste estudo, Vita Easyshade, é um espectrofotômetro que além dos dados CIELab, também oferece a leitura da cor nas escalas Vita Classical e Vita 3D Master. Quando as coordenadas CIELab são analisadas, podese identificar o que ocorre com a cor do objeto medido. Neste estudo, observou-se que nenhum tratamento foi capaz de alterar a luminosidade sem a presença de saliva para a porcelana Noritake e que a mesma, com a presença de saliva teve alteração de $L$ no tratamento $T 1$ (aumento) e restabelecimento de $L$ em T2. Na porcelana Duceram ocorreu alteração inversa. Na ausência de saliva, nota-se diminuição de $L$ em T1, restabelecimento de $L$ em T2 e novamente diminuição de $L$ em T3. Porém com a presença de saliva não se encontrou alteração de luminosidade para a porcelana Duceram (Tabela 5.32)

Quando se comparam apenas os grupos A e B, independente da marca do material, observa-se claramente uma diminuição de $L$ em todos os tratamentos nos grupos com saliva, deixando o material mais escuro (Gráfico 5.3). Quando se compara tal fato com as leituras de cor pelas escalas Classical e 3D Master, pode-se notar que a primeira indica uma oscilação de luminosidade do espécime, sem indicar ao certo o que ocorre (Tabelas 5.1 a 5.5 e 5.15 a 5.19). Já na escala 3D Master obteve-se uma melhor interpretação do que ocorre com a luminosidade (Tabelas 5.8 a 5.12 e 5.22 a 5.26). Esta escala conseguiu identificar aumento de $L$ no grupo com saliva, em ambos os materiais, o que significa um espécime mais escuro.

O mesmo ocorre com a saturação. As coordenadas $\mathrm{CIE}$, $\mathrm{a}^{*}$ e $\mathrm{b}^{*}$ não alteraram com nenhum tratamento sem saliva na porcelana Noritake. Mas na porcelana Duceram, tiveram seus valores diminuídos no tratamento T3 e também em todos os grupos com a presença de saliva, tornando o material menos vermelho e menos amarelo. Na leitura pela escala Classical, a porcelana Noritake foi 
encontrada mais saturada o que não corresponde às coordenadas CIELab. A Duceram mostra que houve alteração de cor no grupo com saliva, porém sem determinar qual foi esta diferença. Assim, constata-se que esta escala não tem precisão suficiente para explicar a alteração de cor encontrada. Já a escala 3D Master apresenta uma oscilação de saturação na porcelana Noritake e mais claramente diminuição de saturação na porcelana Duceram com saliva. Tal identificação corresponde aos achados das coordenadas $a^{*}$ e b*, denotando que esta escala tem mais capacidade de identificar alterações de saturação em alguns casos. Contudo, ela também identificou alteração de matiz na porcelana Noritake com saliva, traduzidas como corpos de provas mais vermelhos o que não corresponde ao encontrado na coordenada $a^{*}$, onde a saliva deixa o espécime menos vermelho. Já na porcelana Duceram, o achado de menor saturação identificado pela escala 3D Master corresponde com o achado CIELab onde a diminuição de b deixou o espécime menos amarelo.

Pode-se afirmar então que a presença de saliva provocou diminuição de L, diminuição de $a^{*}$ e diminuição de $b^{*}$, deixando os materiais mais escuros e menos saturados. As porcelanas Noritake e Duceram não se comportaram igualmente, sendo a Duceram mais sensível às alterações de cor provocadas pela presença de saliva, tornando-se menos saturadas (menos amarela e menos vermelha). Ainda a porcelana Duceram foi a mais sensível ao tratamento T3 sem e com saliva, também se tornando menos amarela e menos vermelha (menos saturada).

Ainda se pode afirmar que nenhum tratamento parece provocar alteração da cor. Porém, nota-se uma tendência a maior mudança da cor para o tratamento overglaze em relação aos demais (Tabelas 5.6, 5.7, 5.13, 5.14, 5.20, 5.21, 5.27 e 
5.28). Observa-se pelo tom claro dos escores e pela quantidade de corpos de prova representados nestas tabelas que existem variações pequenas da leitura de cor.

Para a porcelana Noritake, a diferença entre as medidas sem e com saliva é mais evidente do que para a porcelana Duceram (Gráficos 5.1, 5.4 e 5.7).

Assim, os achados obtidos pelas escalas de cor não são condizentes com os achados das coordenadas CIELab. Talvez isto ocorra porque o aparelho trabalhe com uma faixa ou um intervalo de valores correspondentes a cada cor da escala e quando estes valores se repetem ou se cruzam, o aparelho possa se confundir e oferecer duas ou três cores para a leitura da escala Classical. A escala 3D Master parece ter um pouco mais de precisão, embora tenha identificado uma alteração de matiz não condizente com os achados CIELab. Portanto, deve-se afirmar que o espectrofotômetro intraoral Easyshade é aceitável para uso clínico de medição de cor, porém é falho em algumas interpretações, não devendo ser utilizado como fornecedor de dados confiáveis usados em pesquisa científica. A comparação da leitura de cor feita por ele deveria ser futuramente testada utilizando-se um espectrofotômetro já consagrado no meio científico.

Outra forma de se medir diferença de cor com grande frequência utilizada na literatura é o cálculo do $\Delta \mathrm{E}$. É uma medida absoluta que utiliza os dados $\mathrm{L}, \mathrm{a}^{*}$ e b* na fórmula $\Delta \mathrm{E}=[(\Delta \mathrm{L}) 2+(\Delta \mathrm{a}) 2+(\Delta \mathrm{b}) 2] 1 / 2$. Entretanto, como há uma grande diferença na magnitude das escalas de $L$, $a^{*}$ e $b^{*}$, alguns autores defendem a padronização dessas três medidas, já que utilizando da maneira original, a medida $\Delta E$ depende quase que exclusivamente de $L$ (Gráfico 6.1 e Tabela 6.1). 


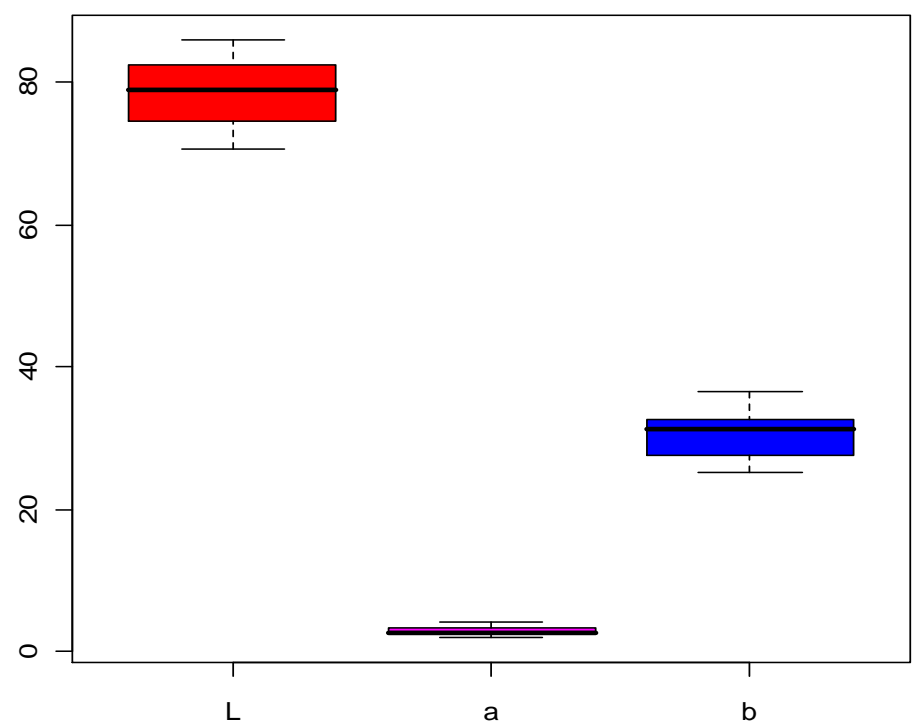

Gráfico 6.1 - Magnitudes comparadas de L, a* e b*

Tabela 6.1 - Valores de variância entre L, $a^{*}$ e b*

\begin{tabular}{|c|c|c|c|}
\hline & $\mathrm{L}$ & $\mathrm{a}$ & $\mathrm{b}$ \\
\hline Mínimo & 70,7 & 2,0 & 25,2 \\
\hline Máximo & 86,0 & 4,2 & 36,5 \\
\hline Amplitude & 15,3 & 2,2 & 11,3 \\
\hline Média & 82,5 & 2,9 & 30,8 \\
\hline Variância & 17,97 & 0,32 & 9,63 \\
\hline
\end{tabular}

No presente trabalho foram calculados os valores de $\Delta \mathrm{E}$ comparando-se os valores obtidos após cada tratamento com os de referência (T0) para os grupos sem saliva (A) e com saliva (B). Conforme as tabelas 5.6 .1 e 5.6.2, nota-se que $\Delta \mathrm{E}$ para a porcelana Noritake do grupo T1A e T2A é menor que 1, o que se encontra na literatura como sendo o menor valor que um indivíduo treinado em visualização de cor conseguiria identificar. Isto quer dizer que o desgaste provocado pela ponta 
Dura-Green e o glazeamento a frio não foram suficientes para provocar alteração de cor visível. Já o overglaze (Grupo T3A) provocou um $\Delta \mathrm{E}$ de valor ainda considerado baixo, porém maior que 1 , sendo assim, alguns indivíduos podem agora identificar alguma diferença de cor. Nos grupos com saliva, os valores de $\Delta \mathrm{E}$ da porcelana Noritake aumentaram, foram todos maiores que 1, porém abaixo do limite visível, sugerindo que a saliva aumentou a diferença entre cores (Tabela 5.44).

$\mathrm{Na}$ porcelana Duceram o comportamento de $\Delta \mathrm{E}$ foi diferente. Todos os valores do grupo A foram maiores que os da porcelana Noritake o que sugere maior alteração da cor, porém todos permaneceram abaixo do limite visível. Quando calculado o $\Delta \mathrm{E}$ para grupo $\mathrm{B}$, os valores encontrados foram menores que nos grupos A, denotando que a saliva diminuiu ou mascarou um pouco a diferença de cor (Tabela 5.45).

Todos estes valores de $\Delta \mathrm{E}$ encontram-se em concordância com Sarac et al. (2006) que constataram em seu estudo que todas as técnicas de polimento afetaram a cor da porcelana, porém que os valores de $\Delta \mathrm{E}$ ficaram abaixo do limite 3 , aceitável ao olho humano. Esse conceito já era esperado, pois Bilmeyer e Saltzman (1981) haviam descrito que qualquer desgaste promovido sobre uma superfície cerâmica para ajuste da peça deveria provocar alteração da cor original da mesma (após o glaze) porque a cor se relaciona à luz refletida associada à superfície em questão.

É por esta razão que alguns autores sugerem que diferentes materiais de polimento causam alteração na textura superficial da porcelana e que após qualquer desgaste a peça deveria sofrer outra aplicação de glaze (AL-WAHADNI, 2006); glaze este chamado de glaze natural, para se obter novo escoamento do material com uma superfície mais regular, o fechamento de eventuais fendas da superfície e recriar as características de brilho e lisura superficiais (AGRA, 2005). 
Por outro lado, esta nova queima ao forno deve ser feita com parcimônia, pois outros estudos têm mostrado que o maior o número de queimas da porcelana provoca mudanças perceptíveis nos valores de La*b* (ULUDAG et al., 2007); e que as diferentes composições das cerâmicas e o número de queimas também alteram a cor do material (OZTURK et al., 2008). Nota-se no presente estudo que T3 foi o tratamento que provocou maiores valores de $\Delta \mathrm{E}$ concordando com achados da literatura. Souza et al. (2009) relataram em seu estudo que o aumento do número de queimas deixou o material mais escuro, assim como os espécimes deste estudo, porém, mais amarelos e mais vermelhos, diferentemente de nossos resultados. Concordamos com Celik et al. (2008) também, pois naquele estudo pode-se constatar que as alterações de cor não são generalizadas, mas que podem ser determinadas pelas diferentes composições de diferentes marcas comerciais. Porém, como encontrado nesta pesquisa, o autor também relatou que encontrou alterações de cor clinicamente aceitáveis.

$\mathrm{Na}$ atualidade, a busca pela estética é algo crescente. Novos materiais e novas tecnologias se esforçam em diminuir as limitações inerentes ao tratamento odontológico e oferecem alternativas ou soluções para diversos problemas. O processo de seleção de cor dental oferece dificuldade intrínseca ao processo devido ao mecanismo de visualização de cor e sua subjetividade pelo método convencional ou visual. A sensação cor e suas características físicas como a conhecemos, matiz, saturação e luminosidade merecem especial atenção e uma ciência para seu entendimento, a colorimetria (SHILLINGBURG, 1998; SPROULL, 1973; SPROULL; PRESTON, 2000; TOUATI, 2000). Muitos trabalhos relatam que no método visual de seleção de cor, o profissional sofre diversas interferências que podem alterar a visualização da cor, como a existência de variáveis fisiológicas e psicológicas 
(CAROLI; VIEIRA; PEREIRA, 2007; CARSTEN, 2003; SALESKI, 1972; VIEIRA, 1996; VIEIRA et al., 2001). Outros trabalhos descrevem a dificuldade pela interferência da própria estrutura dental com interrelação do esmalte dental e suas características de espessura, cor e translucidez com a dentina e também suas características de cor e opacidade (BALTZER; KAUFMANN-JINOIAN, 2005; FONDRIEST, 2003). Pode-se ainda descrever as limitações das escalas dentais existentes que não cobrem todo o espectro de cores necessário, ou não possuem um arranjo lógico; ou mesmo da escala 3D Master que apesar de ser mais confiável e de ter uma distribuição mais ordenada é específica para uma dada população, como sendo outros fatores que dificultam o processo de seleção de cor pelo método convencional (AHN; LEE, 2008; ANALOUI et al., 2004; CORCIOLANI et al., 2009; PRESTON, 1985; SCHWABACHER; GOODKIND, 1990; SORENSEN; TORRES, 1987; WEE et al., 2005). Outro fato que, embora, como comprovado por Ferreira (2001), não seja de grande importância, mas ainda assim merece ser conhecido é o metamerismo, um fenômeno no qual dois objetos têm cores semelhantes sob determinada condição de iluminação e que pode interferir no ato da seleção de cor dental (KIM et al., 2007; LEE, 2007).

A existência de diversos aparelhos no mercado, como descrito por Brewer, Wee e Seghi (2004), busca sanar estas dificuldades e oferecer uma ferramenta ao profissional no momento da escolha da cor. O efeito clínico de diferentes sistemas de escalas de cor na seleção dental também mostrou que profissionais com menor experiência clínica necessitam de um sistema que os guiem durante o processo visual de maneira sistemática, podendo utilizar o método objetivo para terem mais sucesso em sua tarefa ou como uma ferramenta educacional (HAMMAD, 2003; HASSEL et al., 2005; KLEMETI et al., 2006; WEE et al., 2005). Esta é a uma das 
razões pelas quais alguns autores descrevem o aprendizado do assunto cor também como facilitação do processo visual (BARNA et al., 1981; CAROLI; VIEIRA; PEREIRA, 2007; CONCEIÇÃO, 2000; SPROULL, 1974).

O insucesso do método visual foi estudado e comprovado por alguns autores (ARMSTRONG, 1985; KAWARAGl et al., 1990; PAUL et al., 2002). O método digital tem sido estudado pelos autores já há alguns anos e a maioria relata suas características de reprodutibilidade, confiabilidade e concordância, além da facilitação de tempo, de seleção e comunicação de cor como suas principiais vantagens (HORN; BULAN-BRADY; HICKS, 1998; KIM-PUSATERI et al., 2009; RAIGRODSKI et al., 2006; ROSA; BONA, 2007; TUNG et al., 2002). Wee et al. (2005) sugerem que o método objetivo seja associado ao método convencional e que a escolha da cor seja feita por uma associação profissional, paciente e aparelho. Pelo menos três estudos analisaram a diferença total de cor de peças de cerâmica confeccionadas a partir da seleção de cor pelo método digital e todos afirmaram que dessa maneira os valores encontrados para $0 \Delta \mathrm{E}$ foram menores do que se utilizando o método convencional (PAUL et al., 2002; PAUL et al., 2004; SILVA et al., 2008).

Contrariamente, outros autores testaram os aparelhos utilizados no método objetivo e não relatam resultados com diferenças significantes entre os dois métodos tanto in vivo como in vitro (DANCY et al., 2003; HUGO; WITZEL; KLAIBER, 2005; OKUBO; KANAWATI; RICHARDS, 1998; WEE et al., 2000; WEE; MONAGHAN; JOHNSTON, 2002). Chu (2003), ainda cita o alto custo desses aparelhos e o gasto com pesquisas sobre este tema que têm sido feitas nos últimos anos.

Pode-se assim, questionar a eficiência e confiabilidade destes aparelhos não somente para uso clínico, mas também em pesquisa científica. 


\section{CONCLUSÃO}

Com base nos dados obtidos neste estudo, pode-se concluir que:

- não houve alteração de cor perceptível ao olho humano de nenhum material sob os tratamentos superficiais realizados. Entretanto, nota-se uma mudança maior da cor para o tratamento overglaze em relação aos demais tratamentos;

- a diferença de cor causada pela presença de saliva na porcelana Noritake e os valores encontrados para a porcelana Duceram foram valores perceptíveis ao olho humano treinado em seleção de cor;

- o tratamento overglaze na porcelana Duceram foi o que maior $\Delta \mathrm{E}$ promoveu, chegando próximo ao limite aceitável;

- na presença de saliva os valores de $\Delta \mathrm{E}$ todos aumentaram para a porcelana Noritake e diminuíram para a porcelana Duceram, indicando que as diferentes composições dos materiais alteram seu comportamento;

- a diferença entre as medidas com saliva e sem saliva para a porcelana Noritake é mais evidente do que para Duceram;

- o aparelho é falho em algumas interpretações, mas é aceitável para o uso clínico de seleção de cor dental;

- o aparelho não é indicado para seleção de cor em estudos científicos;

- as análises dos dados La*b* não são condizentes com as leituras de cor pelas escalas Vita Classical e 3D Master. 


\section{REFERÊNCIAS ${ }^{1}$}

Agra CM. Avaliação quantitative e qualitative de duas cerâmicas frente a diversos tratamentos de superfície [Tese de Doutorado]. São Paulo: Faculdade de Odontologia da USP; 2005.

Ahn JS, Lee YK. Color distribution of a shade guide in the value, chroma and hue scale. J Prosthet Dent 2008;100(1):18-28.

Al-Wahadni A. na in vitro investigation into the surface roughness of two glazed, unglazed and refinished ceramic materials. Quintessence Int 2006;37(4):311-7.

Analoui M, Papkosta E, Cochran M, Matis B. Designing visually optimal shade guides. J Prosthe Den 2004;92(4):371-6.

Armstrong SR. Dentist-laboratory communications. Dent Clin North Am 1985;15(3):577-85.

Baltzer A, Kaufmann-Jinoian V. Shading of ceramic crowns using digital tooth shade matching devices. Int J Comput Dent 2005;8(2):129-52.

Barnna GJ, Taylor JW, King GE, Pelleu Jr GB. The influence of selected light intensities on color perception within the color range of natural teeth. J Prosthet Dent $1981 ; 46(4): 450-3$.

Bilmeyer FVJr, Saltzman M. Principles of color technology. $2^{\text {nd }}$ ed. New York: John Wile; 1981.240 p.

Brewer JD, Wee A, Seghi R. Advances in color matching. Dent Clin N Am 2004;48(2):341-58.

Bussab W, Morettin P. Estatística básica. 5ae ed. São Paulo: Saraiva; 2002.

\footnotetext{
${ }^{1}$ De acordo com Estilo Vancouver. Abreviatura de periódicos segundo base de dados MEDLINE.
} 
Caroli A, Vieira GF, Pereira CAB. Prevalência de indivíduos cor-deficientes entre alunos de Odontologia. Rev ABENO 2007;7:117-21.

Carsten DL. Succesful shade matching - what does it take. Compendium Cont Educ Dent 2003;24(3):175-82.

Celik G, Uludag B, Usumez A, Sahin V, Ozturk O, Goktug G. the effect of repeated firings on the color of an all-ceramic system with two different veneering porcelain shades. J Prosthet Dent 2008;99(3):203-8.

Chu SJ. Color In: Gurel G. The science and art of porcelain laminate veneers. $1^{\underline{a}}$ ed. São Paulo: Quintessence Publishing; 2003. p. 159-206.

Chu SJ, Tarnow DP. Digital shade analysis and verification: a case report and discussion. Pract Proced Aesthet Dent 2001;13(2):129-36.

Conceição EN. Dentística saúde e estética. Porto Alegre: Artes Médicas Sul; 2000.

Corciolani G, Vichi A, Goracci C, Ferrari M. Colour correspondence of a ceramic system in two different shade guides. J Dent 2009;37(2):98-101.

Craig RG, Powers JM. Materiais dentários restauradores. 11aㅡ ed. São Paulo: Santos; 2004.

Culpepper WD. A comparative study of shade-matching procedures. J Prosthet Dent 1970;24(2):166-73.

Dancy WK, Yaman P, Dennison JB, O’Brien WJ, Razzoogg ME. Color measurements as quality criteria for clinical shade matching of porcelain crowns. $J$ Esthet Restor Dent 2003;15(2):114-21.

Dozic A, Kleverlaan CJ, Meegdes M, van der Zel J, Feilzer AJ. The influence of porcelain layer thickness on the final shade of ceramic restorations. J Prosthet Dent 2003;90(6):563-70.

Ferreira ATM. Influência do iluminante na cor de dentes naturais e materiais restauradores estéticos [Dissertação de Mestrado]. São Paulo: Faculdade de Odontologia da USP, 2001. 
Fondriest J. Shade matching in restorative dentistry: the science and strategies. Int J Periodont Rest Dent 2003;23(5):467-79.

Hammad IA. Intrarater repeatability of shade selections with two shade guides. J Prosthet Dent 2003;89(1):50-3.

Hasegwa A, Ikeda I, Kawaguchi. Color and translucency of in vivo natural central incisors. J Prosthe Dent 2000;83(4):418-23.

Hassel AJ, Koke U, Schmitter M, Beck J, Rammelsberg P. Clinical effect of different shade guide systems on the tooth shades of ceramic-veneered restorations. Int $\mathrm{J}$ Prosthodont 2005;18(5):422-6.

Horn AJ, Bulan-Brady J, Hicks L. sphere spectrophotometer vs human evatuation of tooth shade. J Endodon 1998;24(12):786-94.

Hugo B, Witzel T, Klaiber B. Comparison of in vivo and computer - aided tooth shade determination. Clin Oral Investig 2005;9(4):244-50.

Ishikawa-Nagai S, Ishibashi K, Tsuruta O, Weber HP. Reproducibility of tooth color gradation using computer color match technique applied to ceramic restorations. J Prosthet Dent 2005;93(2):129-37.

Jarad FD, Russel MD, Moss BW. The use of digital imaging for colour matching and communication in restorative dentistry. Br Dent J 2005;199(1):43-49.

Kawaragi C, Ishikawa S, Miyoshi F, Furukawa K, Ishibashi K. Evaluations by denists and patients concerning the color of porcelain fused to metal restorations. Dent $\mathrm{J}$ Iwate Med Univ 1990;15:9-17.

Kim SH, Lee YK, Lim BS, Rhee SH, Yang HC. Metameric effect between dental porcelain and porcelain repairing resin composite. Dent Mater 2007 Mar;23(3):374-9.

Kim-Pusateri S, Brewer JD, Davis EL, Wee AG. Reliability and accuracy of four dental shade - matching devices. J Prosthet Dent 2009;101(3):193-9.

Klemeti E, Matela AM, Haag P, Kononen M. Shade selection performed by novice dental professionals and colorimeter. J Oral Rehabil 2006;33(1):31-5. 
Lee YK. Changes in the translucency of porcelain and repairing resin composite by the illumination. Dent Mater 2007 Apr;23(4):492-7.

Macedo H. Dicionário de Física. 1ํㅡ ed. Rio de Janeiro: Nova Fronteira; 1976.

Maindonald J, Braun J. Data analysis and graphics using R. $2^{\text {nd }}$ ed. Cambridge: Cambridge University; 2007.

Munsell AH. A color notation. 11 $1^{\text {th }}$ ed. Baltimore: Munsell Color; 1961.

Okubo SR, Kanawati A, Richards MW, Childress S. Evaluation of visual end instrumental shade matching. J Prosthet Dent 1998;80(6):642-8.

Ozturk O, Uludag B, Usumez A, Sahin V, Celik G. The effect of ceramic thickness and number of firings on the coloro $f$ two all-ceramic systems. J Prosthet Dent 2008;100(2):99-106.

Paul S, Peter A, Pietrobon N, Hammerle CHF. Visual and spectrophotometric shade analysis of human teeth. J Dent Rest 2002;81(8):578-82.

Paul SJ, Peter A, Rodoni L, Pietrobon N. Convencional visual VS spectrophotometric shade taking for porcelain-fused-to-metal crowns: a clinical comparison. Int J Period Dent 2004;24(3):222-31.

Phillips RW. Skinner materiais dentários. 9ª ed. Rio de Janeiro: Guanabara Koogan; 1993.

Preston JD. Current status of shade selection and color matching. Quintessence Int $1985 ; 16(1): 47-58$.

Raigrodski AJ, Chiche GJ, Aoshima H, Spiekerman CF. Efficacy of a computerized shade selection system in matching the shade of anterior metal-ceramic crowns - a pilot study. Quintessence Int 2006;37(10):793-802.

Rosa V, Bona AD. In-office shade matching: from shade guides to spectrophotometers. Clinica- Inter J Braz Dent 2007;3(1):62-8. 
Saleski CG. Color, light, and shade matching. J Prosthet Dent 1972;27(3):263-68.

Sarac D, Sarac YS, Yuzbasioglu E, Bal S. The effects of porcelain polishing systems on the color and surface texture of feldspathic porcelain. J Prosthet Dent 2006;96:122-8.

Schwabacher WB, Goodkind RJ. Three-dimensional color coordinates of natural teeth compared with three shade guides. J Prosthet Dent 1990;64(4):425-34.

Shillingburg Jr H. Considerações estéticas. In: Shillingburg Jr H. Fundamentos de prótese fixa. $3^{\mathrm{a}}$ ed. São Paulo: Quintessence; 1998. cap. 23, p. 343-52.

Silva JD, Park SE, Weber HP, Ishikawa-Nagai S. Clinical Performance of a newly developed spectrophotometric system on tooth color reproduction. J Prosthet Dent 2008;99(5):361-8.

Sorensen JA, Torres TJ. Improved color matching of metal-ceramic restorations. Part I: a systematic method for shade determination. J Prosthet Dent 1987;58(2):133-9.

Souza FCPP, Casemiro LA, Garcia LSR, Cruvinel DR. color stability of dental ceramics submitted to artificial accelerated aging after repeated firings. J Prosthet Dent 2009;101(1):13-8.

Sproull RC. Color matching in dentistry. Part I: The three-dimensional nature of color. J Prosth Dent 1973;29(4):416-24.

Sproull RC. Color matching in dentistry. Part III. Color control. J Prosthet Dent $1974 ; 31(2): 146-54$.

Sproull RC, Preston JD. Entendendo a Cor. In: Goldstein RE. A estética em odontologia. $2^{a}$ ed. São Paulo: Santos; 2000. cap. 10, p. 207-20.

Terry DA. Color matching: Part I - subjective methods. Prac Proced Aesthet Dent 2005a;17(5):347.

Terry DA. Color matching: Part II - objective methods. Prac Proced Aesthet Dent 2005b;17(6):401-2. 
Touati B, Miara P, Nathanson D. Transmissão de luz e cor. In: Touati B. Odontologia estética e restaurações cerâmicas. Trad. de Sérgio Lian B. Martins. São Paulo: Santos; 2000. cap. 4, p. 39-60.

Tung FF, Goldstein GR, Jang S, Hittelman E. The repeatability of an intraoral dental colorimeter. J Prosthet Dent 2002, 88 (6): 585-90.

Uludag B, Usumez A, Sahin V, Eser K, Ercoban E. the effect of ceramic thickness and number of firings on the color of ceramic systems: an in vitro study. J Prosthet Dent 2007;97(1):25-31.

Vieira GF. Avaliação da cor dos dentes em função de uma escala comercial [Tese de Livre Docência]. São Paulo: Faculdade de Odontologia da USP; 1996.

Vieira GF, Caroli A, Amorim J, Matson E. The influence of the surface treatment on the color of two porcelains. Dent Mater J 2001;20(2):127-34.

Vieira GF, Ferreira ATM, Garófalo JC, Agra CM, Caroli A. Cor das facetas. In: Vieira GF, Ferreira AM, Garófalo JC, Agra M, Caroli A. Facetas laminadas. $3^{a}$ ed. São Paulo: Santos; 2004. cap. 5, p. 35-45.

Volpato CAM, Baratieri LN, Monteiro Jr. S.análise intrumental da cor em odontologia: considerações básicas. R Dental Press Estet 2005;2(1):21-31.

Wee AG, Kang EY, Jere D, Beck FM, J. Clinical color match of porcelain visual shade-matching systems. J Esthet Restor Dent 2005;17(6):351-8.

Wee AG, Kang EY, Johnston WM, Seghi RR. Evaluating porcelain color match of different porcelain shade-matching systems. J Esthe Restor Dent 2000;12(5):270-80.

Wee AG, Monaghan P, Johnston WM. Variation in color between intended matched shade and fabricated shade of dental porcelain. J Prosthet Den 2002;87(6):657-66. 